OPEN ACCESS

Edited by:

Nuno Raimundo,

Universitätsmedizin Göttingen,

Germany

Reviewed by:

Fedor F. Severin,

Moscow State University, Russia

Sergio Giannattasio,

National Research Council-Institute

of Biomembranes and Bioenergetics,

Italy

*Correspondence: Paul J. Cullen pjcullen@buffalo.edu

Specialty section:

This article was submitted to

Mitochondrial Research,

a section of the journal

Frontiers in Physiology

Received: 17 November 2016 Accepted: 24 February 2017

Published: 29 March 2017

Citation:

González B, Mas A, Beltran G, Cullen PJ and Torija MJ (2017) Role of Mitochondrial Retrograde Pathway in Regulating Ethanol-Inducible Filamentous Growth in Yeast. Front. Physiol. 8:148 doi: 10.3389/fphys.2017.00148

\section{Role of Mitochondrial Retrograde Pathway in Regulating Ethanol-Inducible Filamentous Growth in Yeast}

\author{
Beatriz González ${ }^{1}$, Albert Mas ${ }^{1}$, Gemma Beltran ${ }^{1}$, Paul J. Cullen ${ }^{2 *}$ and María Jesús Torija ${ }^{1}$ \\ ${ }^{1}$ Departament de Bioquímica i Biotecnologia, Universitat Rovira i Virgili, Tarragona, Spain, ${ }^{2}$ Department of Biological \\ Sciences, University at Buffalo, Buffalo, NY, USA
}

In yeast, ethanol is produced as a by-product of fermentation through glycolysis. Ethanol also stimulates a developmental foraging response called filamentous growth and is thought to act as a quorum-sensing molecule. Ethanol-inducible filamentous growth was examined in a small collection of wine/European strains, which validated ethanol as an inducer of filamentous growth. Wine strains also showed variability in their filamentation responses, which illustrates the striking phenotypic differences that can occur among individuals. Ethanol-inducible filamentous growth in $\Sigma 1278 \mathrm{~b}$ strains was independent of several of the major filamentation regulatory pathways [including fMAPK, RAS-cAMP, Snf1, Rpd3(L), and Rim101] but required the mitochondrial retrograde (RTG) pathway, an inter-organellar signaling pathway that controls the nuclear response to defects in mitochondrial function. The RTG pathway regulated ethanol-dependent filamentous growth by maintaining flux through the TCA cycle. The ethanol-dependent invasive growth response required the polarisome and transcriptional induction of the cell adhesion molecule Flo11p. Our results validate established stimuli that trigger filamentous growth and show how stimuli can trigger highly specific responses among individuals. Our results also connect an inter-organellar pathway to a quorum sensing response in fungi.

Keywords: filamentous growth, pseudohyphal growth, quorum sensing, mitochondria-to-nucleus pathway, krebs cycle

\section{INTRODUCTION}

Fungal species represent a diverse group of microorganisms. Most fungal species exist in the wild. Other species live in commensal or pathogenic relationships with host organisms, while others still have been domesticated for food and technological benefits. Saccharomyces sensu stricto represents a group of highly related yeasts (Borneman and Pretorius, 2015). Saccharomyces cerevisiae and its relatives are commonly used in research laboratories and a variety of industrial processes. The ability of Saccharomyces to produce ethanol from several sugar sources makes it an essential component of the brewing and wine-making industries. Yeast not only produces ethanol as the major by-product of the alcoholic fermentation of sugars but also produces minor compounds such as aromatic (or fusel) alcohols that impart flavor and bouquet to wines. These properties have been studied to improve ethanol production and to understand the molecular basis of nutrient 
sensing and regulatory mechanisms in eukaryotes (Fleet and Heard, 1993; Ribéreau-Gayon et al., 2000; Beltran et al., 2004, 2008; Alper et al., 2006; Zaman et al., 2008).

Many fungal species, including yeasts, can undergo filamentous growth. Filamentous growth in yeast is a developmental foraging response, where cells become elongated and grow in connected chains (Gimeno et al., 1992; Kron et al., 1994). In some settings, cells can penetrate surfaces, which is known as invasive growth (Roberts and Fink, 1994). Some fungal species grow as multinucleate hyphae. Other species, like $S$. cerevisiae, produce pseudohyphae where cells undergo cytokinesis at each cell division. Filamentous growth has been extensively studied in yeast and other species, particularly pathogens, which require filamentous growth for virulence (Madhani and Fink, 1998; Lengeler et al., 2000; Polvi et al., 2015). Such studies have led to insights into the triggers, signaling pathways and transcriptional targets that control developmental responses in fungi and other eukaryotes.

One inducer of filamentous growth is nitrogen limitation (Gimeno et al., 1992). Another is the limitation of fermentable sugars like glucose (Cullen and Sprague, 2000). The morphogenetic response to limiting glucose is mediated by several pathways, including a mitogen-activated protein kinase pathway called the filamentous growth (fMAPK) pathway (Saito, 2010; Karunanithi and Cullen, 2012; Adhikari and Cullen, 2014; Adhikari et al., 2015), the AMP-dependent kinase AMPK Snflp (Celenza and Carlson, 1989; Woods et al., 1994; Lesage et al., 1996; Cullen and Sprague, 2000; McCartney and Schmidt, 2001; Kuchin et al., 2002), and the RAS-cAMP-protein kinase A (PKA) pathway (Toda et al., 1985; Gimeno et al., 1992; Mosch et al., 1996, 1999; Colombo et al., 1998; Robertson and Fink, 1998a,b; Rupp et al., 1999b; Robertson et al., 2000; Pan and Heitman, 2002). Filamentous growth is also regulated by the Rim 101 pathway, which regulates the response to $\mathrm{pH}$ (Lamb et al., 2001; Lamb and Mitchell, 2003; Barrales et al., 2008). Other regulators include the chromatin remodeling complex Rpd3(L) (Carrozza et al., 2005; Barrales et al., 2008; Ryan et al., 2012), the tRNA modification complex Elongator (Krogan and Greenblatt, 2001; Winkler et al., 2001; Petrakis et al., 2004; Li et al., 2007; Svejstrup, 2007), and the Pho80p-Pho85p cyclin and cyclin-dependent kinase (Measday et al., 1997; Huang et al., 2002, 2007; Shemer et al., 2002; Moffat and Andrews, 2004; Chavel et al., 2014). In addition to these pathways, genetic (Lorenz and Heitman, 1998; Palecek et al., 2000), genomic and proteomic screens (Jin et al., 2008; Xu et al., 2010; Ryan et al., 2012) have identified many other proteins and pathways that impact filamentous growth. Thus, filamentous growth resembles cell differentiation

\footnotetext{
Abbreviations: AMPK, AMP-dependent protein kinase; DIC, differentialinterference-contrast; fMAPK, filamentous growth mitogen activated protein kinase; HOG, high osmolarity glycerol pathway; MM, minimal medium; OD, optical density; PWA, plate-washing assay; PKA, protein kinase A; qPCR, quantitative polymerase chain reaction; $\mathrm{SAD}$, synthetic medium with ammonium and dextrose; SALG, synthetic medium with ammonium and low glucose; SLAD, synthetic medium with dextrose and low-ammonium; TOR, target of rapamycin; TCA, tricarboxylic acid; Trp-OH, tryptophol; v/v, volume-to-volume percent; YNB, yeast nitrogen base; YPD, yeast peptone dextrose.
}

in metazoans, where global reorganization of cellular processes results in the construction of a new cell type.

Fungal species also utilize small molecules to interpret information about their environment. Like many other microbial species (Miller and Bassler, 2001; Parsek and Greenberg, 2005; Rumbaugh et al., 2009), S. cerevisiae exhibits quorum-sensing responses (Hlavacek et al., 2009; Prunuske et al., 2012). Yeast can sense and respond to ammonia (Palkova et al., 1997), aromatic (fusel) alcohols (Chen and Fink, 2006), and ethanol (Dickinson, 1994, 1996; Lorenz et al., 2000). By products of the Ehrlich reactions (Hazelwood et al., 2008), fusel alcohols are formed by conversion of several amino acids into glutamate as a nitrogen source under nitrogen-limiting conditions (Ljungdahl and Daignan-Fornier, 2012). Fusel alcohols are produced at higher levels in nitrogen-limiting medium and sensed in a densitydependent manner by a PKA-dependent mechanism to regulate filamentous growth (Chen and Fink, 2006). Multiple fungal species produce and sense a variety of aromatic alcohols, which may impart selectivity in this type of cellular communication (Chen et al., 2004; Chen and Fink, 2006; Sprague and Winans, 2006; Kruppa, 2008; Langford et al., 2013). Recent efforts have expanded the diversity alcohols that can be sensed and measured their impact on fungal behavioral responses (Ghosh et al., 2008; Wuster and Babu, 2010; Sharma and Prasad, 2011; Albuquerque and Casadevall, 2012; Bojsen et al., 2012; Avbelj et al., 2015; Williams et al., 2015). An open question has been to identify the regulatory pathways that control alcoholmediated morphogenesis and understand how cells detect and respond to these stimuli. Addressing this problem has a practical benefit, as industrial manipulation of yeast may be accelerated by understanding density-dependent growth and behavioral responses (Westman and Franzen, 2015).

To better understand common and unique elements of the filamentous growth response, a diverse collection of strains was examined from the "wine/European" group (Goffeau et al., 1996; Wei et al., 2007; Borneman et al., 2008, 2011; Argueso et al., 2009; Liti et al., 2009; Novo et al., 2009). Most strains tested underwent filamentous growth in response to limiting glucose, limiting nitrogen, or the presence of ethanol or fusel alcohols. A specific role for the mitochondrial retrograde (RTG) pathway, which controls the response to compromised mitochondrial function (Liu and Butow, 2006) and is known to regulate filamentous growth (Jin et al., 2008; Chavel et al., 2010, 2014; Aun et al., 2013; Starovoytova et al., 2013), was identified as a specific regulator of ethanol-inducible invasive growth. RTG regulated TCA cycle flux in response to ethanol to modulate filamentous growth. Thus, the study connects an inter-organellar signaling pathway to a quorum-sensing morphogenetic response in fungi.

\section{MATERIALS AND METHODS}

\section{Yeast Strains, Media, and Growth Conditions}

Yeast strains are described in Table 1. Standard media was used (Rose et al., 1990). Yeast strains were generated by polymerase chain reaction (PCR)-based homologous recombination 
TABLE 1 | Yeast strains used in the study.

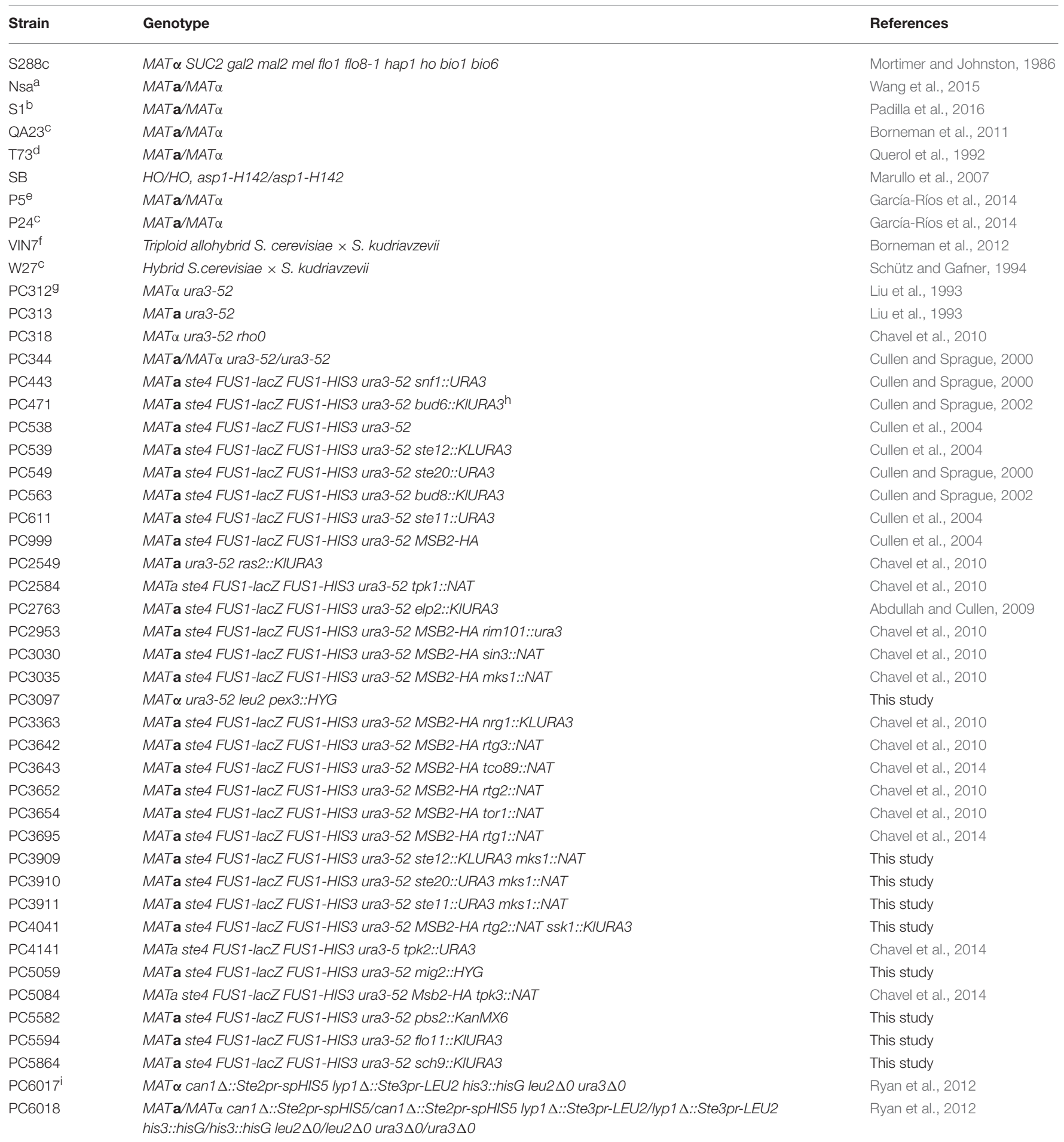

\footnotetext{
${ }^{a}$ Natural isolate from wine.

${ }^{b}$ Natural isolate from wine (CECT 13132).

${ }^{\circ}$ Commercial wine yeast Lalvin ${ }^{\circledR}$ Lallemand.

${ }^{d}$ Commercial wine yeast Lalvin ${ }^{\circledR}$ Lallemand (CECT1894).

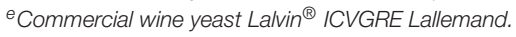

${ }^{f}$ Commercial wine yeast AWR/1539 ${ }^{\circledR}$.

${ }^{9}$ All PC strains are in the $\Sigma 1278 b$ strain background.

${ }^{\text {h}}$ KIURA3 refers to the Kluyveromyces lactis URA3 gene cassette.

'Mutants derived from this strain were constructed in a genomic collection and were also tested in the study.
} 
techniques using auxotrophic or antibiotic resistant markers (Goldstein and McCusker, 1999). Yeast were grown on YPD (2\% peptone, $1 \%$ yeast extract, $2 \%$ glucose, and $2 \%$ agar), minimal medium $[(\mathrm{MM}) 1 \mathrm{X}$ Yeast Nitrogen Base (YNB) without amino acids or ammonium, $2 \%$ glucose, and $10 \mathrm{mM}$ $\left(\mathrm{NH}_{4}\right)_{2} \mathrm{SO}_{4}$ ], synthetic media [(SD) $1 \mathrm{X}$ YNB, 2\% glucose, and $\left.37 \mathrm{mM}\left(\mathrm{NH}_{4}\right)_{2} \mathrm{SO}_{4}\right]$ with ammonium and dextrose [(SAD) $1 \mathrm{X}$ $\mathrm{YNB}, 1 \%$ glucose, and $\left.37 \mathrm{mM}\left(\mathrm{NH}_{4}\right)_{2} \mathrm{SO}_{4}\right]$, or with ammonium and low glucose [(SALG) $1 \mathrm{X}$ YNB, $0.5 \%$ glucose, and $37 \mathrm{mM}$ $\left(\mathrm{NH}_{4}\right)_{2} \mathrm{SO}_{4}$ ]. To evaluate pseudohyphal growth, yeast were grown on synthetic medium with dextrose and low-ammonium [(SLAD) $1 \mathrm{X}$ YNB, 2\% glucose, $50 \mu \mathrm{M}\left(\mathrm{NH}_{4}\right)_{2} \mathrm{SO}_{4}$, and $2 \%$ agar (Gimeno et al., 1992)]. Media was supplemented with uracil for auxotrophic mutants. For some experiments, SD and SLAD media were supplemented with $500 \mu \mathrm{M}$ tryptophol, tyrosol, or phenylethanol and $2 \%(\mathrm{v} / \mathrm{v})$ ethanol. The CIT2-lacZ plasmid has been described (Liu and Butow, 1999) and was provided by Dr. Zhengchang Liu (Louisiana State University, New Orleans). Beta-galactosidase assays were performed as described (Chavel et al., 2014).

\section{Pseudohyphal Growth Assays}

Examination of pseudohyphae was determined as described (Gimeno et al., 1992). Strains were grown for $16 \mathrm{~h}$ at $28^{\circ} \mathrm{C}$ in $\mathrm{MM}$ and harvested by centrifugation (1,000 rpm for $3 \mathrm{~min}$ ). To obtain single colonies, cells were diluted by a factor of $10^{6}$ in sterile water, and $100 \mu \mathrm{L}$ of cells were spread onto media (SAD, SALG, and SLAD). Plates were incubated at $28^{\circ} \mathrm{C}$ and observed daily for $10 \mathrm{~d}$ by microscopy for colony morphology.

\section{Invasive Growth Assays}

Strains were grown for $16 \mathrm{~h}$ at $30^{\circ} \mathrm{C}$ in $\mathrm{MM}$, harvested by centrifugation (10,000 rpm for $3 \mathrm{~min}$ ) at an optical density (O.D. $\mathrm{A}_{600}$ ) of 2.0, washed once in sterile water and resuspended in sterile water. Ten microliters of cells were spotted on semisolid agar media. Plates were incubated at $28^{\circ} \mathrm{C}$. Invasive growth was determined by the plate-washing assay (Roberts and Fink, 1994). Colonies were photographed before and after washing over a 10 days period. Plates were washed in a stream of water (soft wash) and colonies were rubbed from the surface with a gloved finger (hard wash). ImageJ (http://rsb.info.nih. gov/ij/) was used to quantitate invasive growth (Zupan and Raspor, 2008). Background intensity was determined for each spot and subtracted from the densitometry of the area of invaded cells. Densitometric analysis was performed on invasive patches over multiple days. Tukey's $t$-test was used to determine statistical significance and generate $p$-values. The Shapiro-Wilk and Jarque-Bera normality tests showed that the data fit a normal distribution. A non-parametric statistics test (Wilcoxon test) showed the same results as the Tukey's $t$-test.

\section{Quantitative Polymerase Chain Reaction (qPCR) Analysis}

Quantitative PCR was performed as described (Beltran et al., 2004). Ethanol addition stimulated the expression of FLO11 at all-time points except $24 \mathrm{~h}$. Strains were grown in MM for $24 \mathrm{~h}$ at $28^{\circ} \mathrm{C}$, washed with MiliQ sterile water (Millipore Q-PODTM
Advantage A10) and resuspended in the indicated media at an O.D. $\mathrm{A}_{600}$ of 2.0. Cells were inoculated in SLAD media and in $\mathrm{SAD}$ media, and samples were taken at $2 \mathrm{~h}$. To study the effect of nitrogen concentration in FLO11 expression, strains were grown in $\mathrm{MM}$ for $24 \mathrm{~h}$ at $28^{\circ} \mathrm{C}$, washed with MiliQ sterile water (Millipore Q-PODTM Advantage A10) and resuspended in SAD and SLAD media at an O.D. A 600 of 2.0. Samples were taken at $2 \mathrm{~h}$ to analyze the FLO11 expression. To study the effect of ethanol in FLO11 expression, cells were inoculated at an O.D. $\mathrm{A}_{600}$ of 2.0 in SLAD medium with or without ethanol (2\% v/v) Samples were taken at $45 \mathrm{~min}, 2,8$, and $24 \mathrm{~h}$. RNA extraction was performed using an RNeasy Mini Kit (Qiagen). RNA concentration was adjusted to $320 \mathrm{ng} / \mathrm{\mu L}$. Reverse transcription was performed using SuperScript ${ }^{\circledR}$ III Reverse Transcriptase (Invitrogen) and Oligo (dt) 20 Primer (Invitrogen).

qPCR was performed using an Applied Biosystems 7300 Fast Real-Time PCR System (Applied Biosystems, USA). SyberGreen master mix was used according to the manufacturer's instructions (Applied Biosystems, USA). Reactions contained $25 \mu \mathrm{L}$ sample $(5 \mu \mathrm{L}$ cDNA, $1 \mu \mathrm{M}$ each primer, $10 \mu \mathrm{L}$ SyberGreen master mix, $\mathrm{H}_{2} 0$ q.s.p. $25 \mu \mathrm{L}$ ). The starting quantity of genes was normalized with ACT1 (Chavel et al., 2010). Relative gene expression was calculated using the $2^{-\Delta \mathbf{C t}}$ formula, where $\mathrm{Ct}$ is defined as the cycle at which fluorescence was determined to be statistically significant above background; $\triangle \mathrm{Ct}$ is the difference in $\mathrm{Ct}$ of the FLO11 gene and housekeeping gene (ACT1). The primers used were FLO11 forward (5' ${ }^{\prime}$ CACTTTTGAAGTTTATGCCACACAAG$\left.3^{\prime}\right)$ and FLO11 reverse (5'-CTTGCATATTGAGCGGCACTAC$\left.3^{\prime}\right)$ based on Chen and Fink (2006), and ACT1 forward (5'-TGGATTCCGGTGATGGTGTT-3') and ACT1 reverse $\left(5^{\prime}\right.$ CGGCCAAATCGATTCTCAA-3').

\section{Microscopy}

Differential-interference-contrast (DIC) and bright-field microscopy was performed using an Axioplan 2 fluorescent microscope (Zeiss) with a PLAN-APOCHROMAT 100X/1.4 (oil) objective (N.A. 0.17). Digital images were obtained with the Axiocam MRm camera (Zeiss). Axiovision 4.4 software (Zeiss) was used for image acquisition and analysis and for rendering 3D Z-stack images. Images were further analyzed in Adobe Photoshop, where adjustments of brightness and contrast were made.

\section{RESULTS}

\section{Exploring Filamentous Growth in a Collection of Wild and Industrial Yeast Strains}

To understand the common and unique features of filamentous growth in yeast, a collection of wild and industrial yeast strains used in wine making was examined (Table 1). Strains were compared to $\sum 1278 \mathrm{~b}$, a well-characterized strain background that undergoes filamentous growth (Gimeno et al., 1992), and S288c, which is commonly used in research laboratories (Mortimer and Johnston, 1986) but has acquired mutations 
due to genetic manipulation that render it unable to undergo filamentous growth (Liu et al., 1996; Dowell et al., 2010; Chin et al., 2012).

One aspect of filamentous growth is invasive growth, which can be assessed by the plate-washing assay (PWA), and which measures penetration of filamentous cells into surfaces (Roberts and Fink, 1994). Invasive growth in nutrient-rich (SAG) conditions was compared to conditions that induce filamentous growth, nitrogen limitation (SLAD; Gimeno et al., 1992) and glucose limitation (SALG; Cullen and Sprague, 2000) as shown in Figure 1A. The results were quantitated by densitometric analysis (Figure 1B). As expected, S288c did not undergo invasive growth, and $\sum 1278 \mathrm{~b}$ underwent invasive growth that was higher in media lacking glucose or nitrogen (Figure 1A, washed and Figure 1B). Most wine strains underwent invasive growth, which was stimulated in nitrogen- and glucose-limited medium (including VIN7, W27, QA23, T73, SB, and S1; Figures 1A,B). Three strains showed a different trend: P5 invaded equally well in glucose-rich and glucose-limiting media, P24 did not invade nitrogen-limiting medium, and Nsa showed constitutive invasion. Moreover, the pattern of invasive growth varied widely among strains (Figure 1A).

Another aspect of filamentous growth is pseudohyphal growth, which can be measured by microscopic examination of colony peripheries (Gimeno et al., 1992). As expected, S288c did not form pseudohyphae, and $\sum 1278 \mathrm{~b}$ formed pseudohyphae in nitrogen-limiting medium (Figure 1C, SLAD). Most strains formed pseudohyhae in nitrogen-limiting media (Figure 1C, including VIN7, W27, QA23, T73, SB, P5, S1, and Nsa), except SB, which did not form pseudohyphae until day 16 (for Figure 1C, day 5 is shown) and P24, which did not form pseudohyphae by day 20 when the experiment was terminated. The pattern of pseudohyphae varied among strains. With the exception of Nsa, which formed pseudohyphae in glucose- (Figure S1A, Nsa SALG, arrow) and nitrogen-limiting media, all other strains formed pseudohyphae exclusively under nitrogen-limitng conditions. Invasive and pseudohyphal growth require cell adhesion mediated by the flocculin Flo11p (Lambrechts et al., 1996; Lo and Dranginis, 1996; Guo et al., 2000). FLO11 expression is induced during filamentous growth (Rupp et al., 1999a). A subset of wine strains that were tested all showed induction of FLO11 expression under nitrogen-limiting conditions (Figure S1B). Therefore, above results agree with the widely accepted notion that glucose and nitrogen limitation are general inducers of filamentous growth.

Ethanol also stimulates filamentous growth (Dickinson, 1994, 1996; Lorenz et al., 2000). Ethanol induced filamentous growth specifically in nitrogen-limiting medium (Figure S2A) and showed a maximal effect at a concentration of $2 \%$ (Figure S2B). At this concentration, ethanol did not impact growth (Figure S2C; yeast can survive in 12\% ethanol; Lleixà et al., 2016). Thus, tests were performed at $2 \%$ ethanol in nitrogen-limiting media. As expected, S288c did not show invasive growth by the addition of ethanol (Figures 2A-C), and $\sum 1278 \mathrm{~b}$ showed ethanol-inducible invasive growth (Figures 2A,B). In particular, cells invaded the agar more robustly (Figures 2A,B), and pseudohyphae formed at earlier time points (Figure $2 \mathrm{C}$, colonies were grown for 2 days compared to 5 days in Figure 1C). With the exception of P24 and Nsa, most strains showed increased invasive growth in response to ethanol (Figures 2A-C including VIN7, W27, QA23, T73, SB, S1, and P5). By these criteria, ethanol can also be viewed as a general inducer of filamentous growth. The fusel alcohol tryptophol stimulates filamentous growth in $\sum 1278$ b strains (Figure S3; Chen and Fink, 2006). Tryptophol stimulated invasive growth of most wine strains in nitrogenrich $(\mathrm{SAD})$ but not nitrogen-limiting (SLAD) medium (Figure S3, including VIN7, W27, QA23, T73, and S1). Thus, in line with previous studies, fusel alcohols like tryptophol are general inducers of filamentous growth.

\section{Major Filamentation Regulatory Pathways are not Required for Ethanol-Inducible Filamentous Growth}

We focused on ethanol-inducible filamentous growth because ethanol was a stronger inducer of filamentous growth than fusel alcohols. How ethanol is sensed and triggers filamentous growth has not been extensively studied. The ethanol response occurred in diploid (Figure 2) and haploid (Figure 3) strains of the $\sum 1278 \mathrm{~b}$ background, which facilitated genetic analysis of the response.

Signaling pathways known to regulate filamentous growth were tested for a role in regulating ethanol-inducible filamentous growth. Specifically, mutants were tested that lack key regulators of fMAPK (ste11 $\Delta$; Ste11p is the MAPKKK), Ras2p-cAMP-PKA (ras $2 \Delta$ ) and PKA (Tpk in yeast) subunits Tpk1p, Tpk2p, and

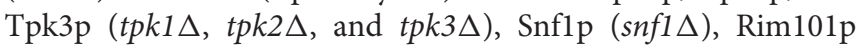
$($ rim $101 \Delta), \operatorname{Rpd} 3 \mathrm{p}(\mathrm{L})(\sin 3 \Delta)$, Elongator $($ elp $2 \Delta)$, and Pho85p (pho85 $\Delta$ ). Surprisingly, all of the mutants showed enhanced invasive growth in media containing ethanol (Figures 3A,B). The examination of colony perimeters generally bore this out, either showing enhanced filament formation or clumpiness (Figure 3C, arrows), which is indicative of elevated cell-cell adhesion. Colony perimeters did not show a change for the ste $11 \Delta$ and rim101 $\Delta$ mutants. Thus, fMAPK and Rim101 pathways may play some role in mediating ethanol-dependent filamentous growth. In summary these results show that ethanol exerts its effect on filamentous growth independent of several of the major regulatory pathways that control filamentous growth.

Unexpectedly, several mutants did not show an invasive growth defect in SLAD media. Specifically, the rim101 $\Delta, \sin 3 \Delta$, snf1 $\Delta$, elp $2 \Delta$, and pho85 $\Delta$ mutants invaded the agar as well as or better then wild-type cells [Figures $\mathbf{3 A , B} ; t p k 3 \Delta$ is not defective for invasive growth (Robertson and Fink, 1998a; Robertson et al., 2000; Chavel et al., 2010)]. We have previously shown that the rim101 $\Delta$ (Chavel et al., 2014), $\sin 3 \Delta$ (Chavel et al., 2010), snf1 $\Delta$ (Cullen and Sprague, 2000), elp2s (Abdullah and Cullen, 2009), and pho85 (Chavel et al., 2014) mutants have an invasive growth defect on rich media, and we verified that phenotype here (Figure S4A; YPD). Thus, there may be differences in the roles these pathways play in regulating 


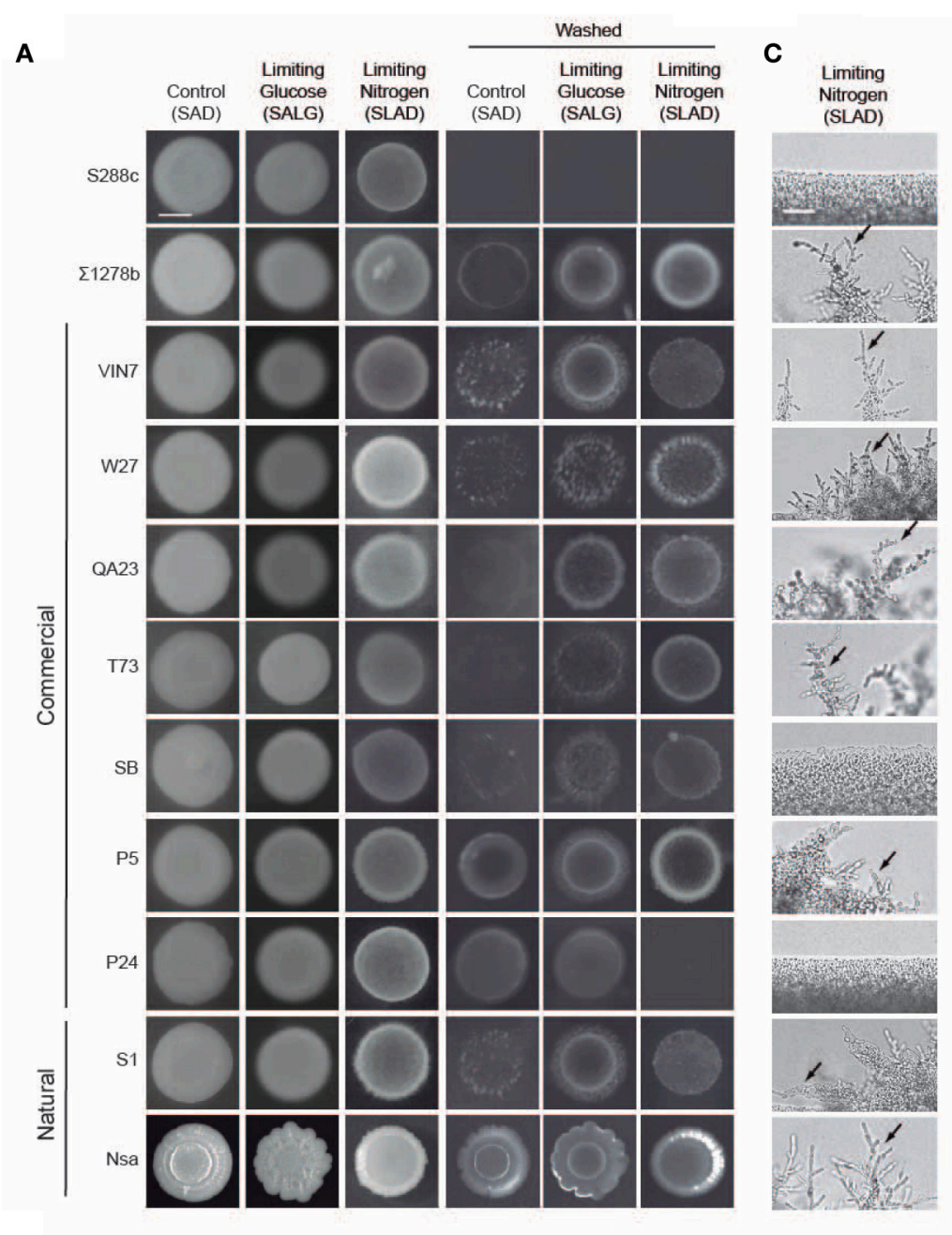

B

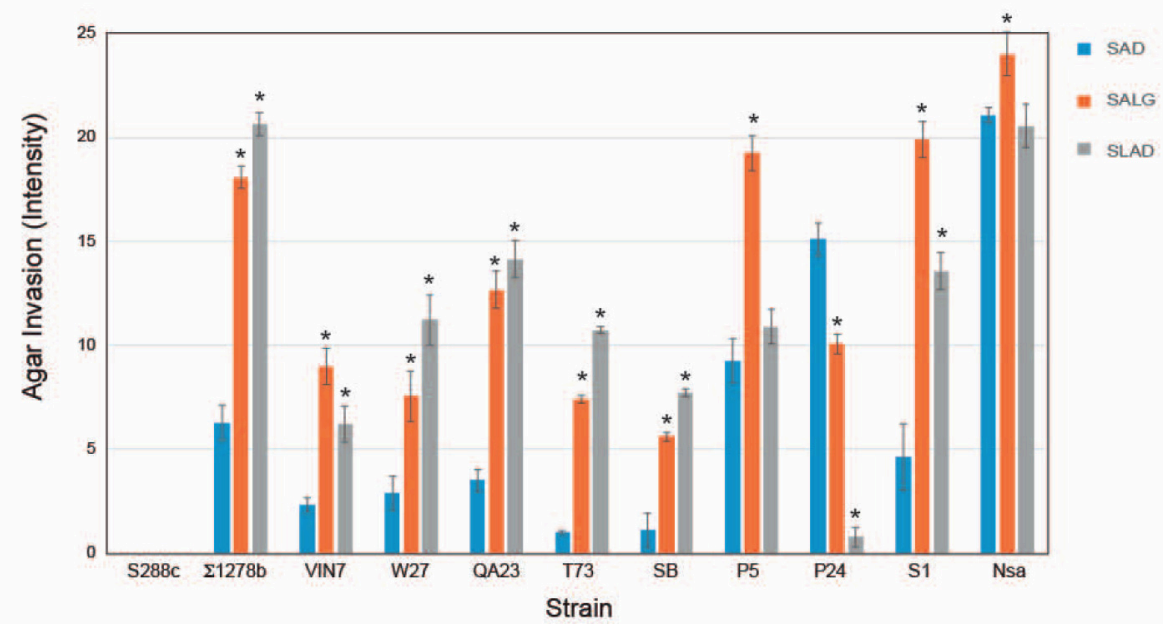

FIGURE 1 | Filamentous growth phenotypes of wine strains. (A) Plate-washing assay (PWA). Equal concentrations of cells $\left(\mathrm{OD}_{600} \mathrm{~nm}=2\right)$ were spotted in 10 $\mu \mathrm{L}$ aliquots onto the indicated media. Plates were incubated for 5 days at $30^{\circ} \mathrm{C}$ and washed in a stream of water. Bar, $5 \mathrm{~mm}$. (B) Quantitation of invasive growth in panel (A) by densitometry. Cells were spotted in triplicate, and the average values are shown. Error bars represent the standard difference between experiments. Asterisk denotes a $p<0.01$ for samples relative to each strain's invasion in SAD. (C) Pseudohyphal growth of micro-colonies. Cells were grown for 3 days in minimal medium (MM) at $30^{\circ} \mathrm{C}$, diluted by a factor of $10^{6}$ and spotted onto SLAD media. Plates were incubated for 5 days. Colonies were examined by microscopy at $40 \mathrm{X}$ magnification. A representative image is shown. Bar, $25 \mu \mathrm{m}$. Arrows mark examples of pseudohyphae. 

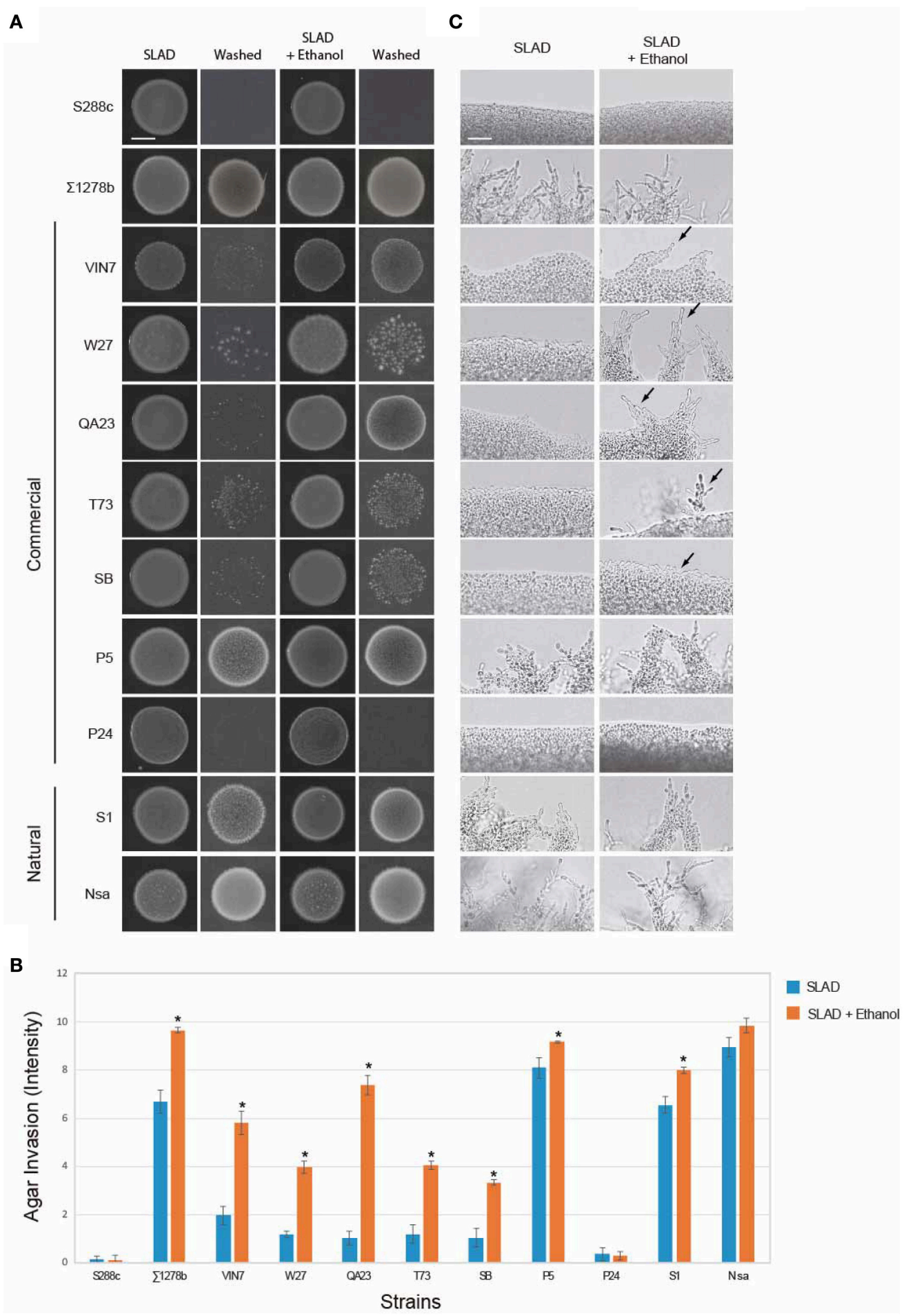

FIGURE 2 | Response of wine strains to ethanol. (A) PWA of cells spotted onto nitrogen-limited medium (SLAD) with or without ethanol (2\% v/v). Plates were incubated for 2 days at $30^{\circ} \mathrm{C}$ and washed in a stream of water. Bar, $5 \mathrm{~mm}$. (B) Quantitation of invasive growth in panel (A) by densitometry, performed as described in Figure 1B. Cells were spotted in triplicate, and the average values are shown. Error bars represent the standard difference between experiments. Asterisk denotes a $p<0.01$ for samples relative to each strain's invasion in SLAD. (C) Microscopy of colony perimeters with or without ethanol at $40 \mathrm{X}$ magnification. Bar, $25 \mu \mathrm{m}$. Arrows mark examples of pseudohyphae. 

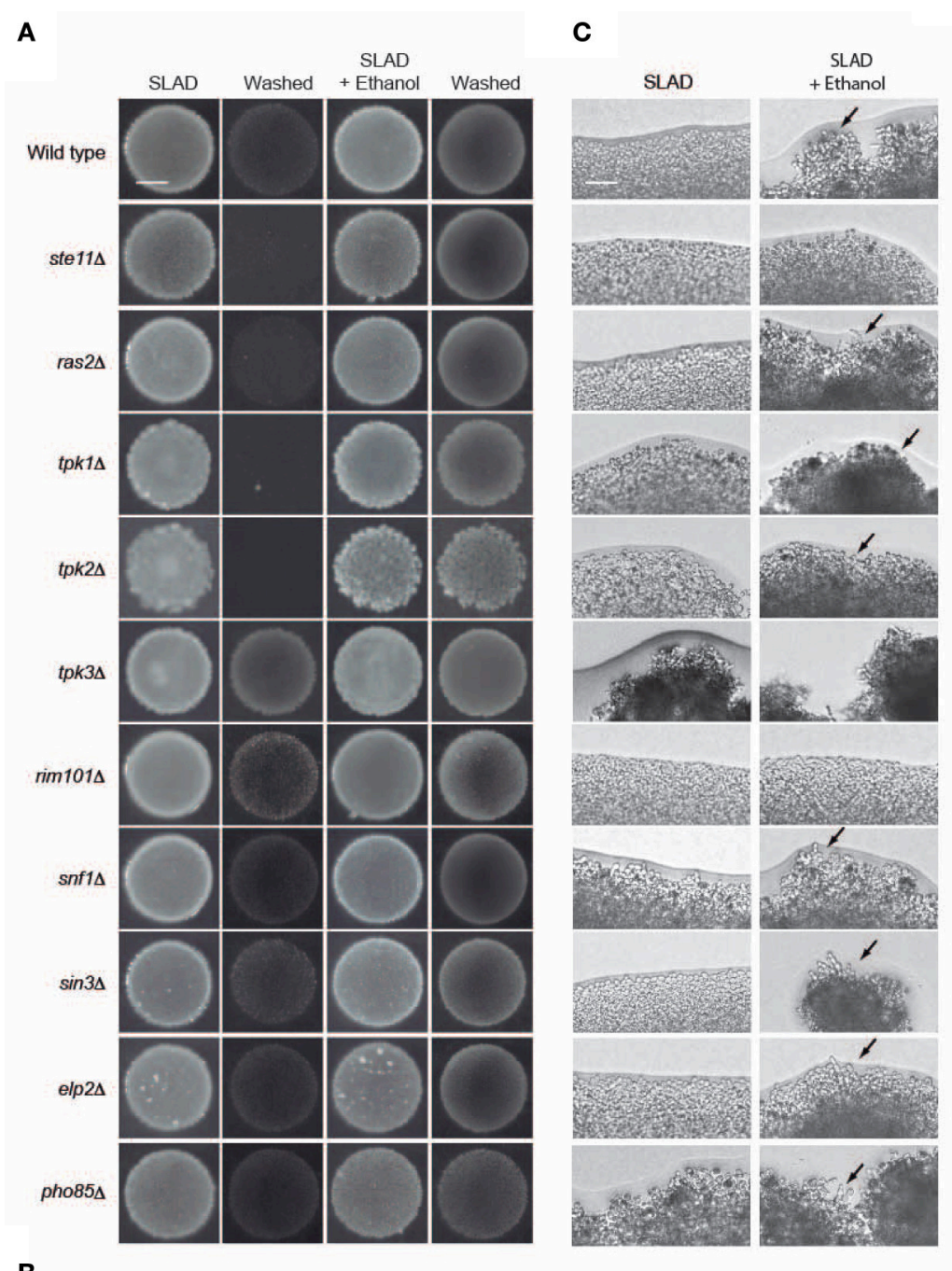

B

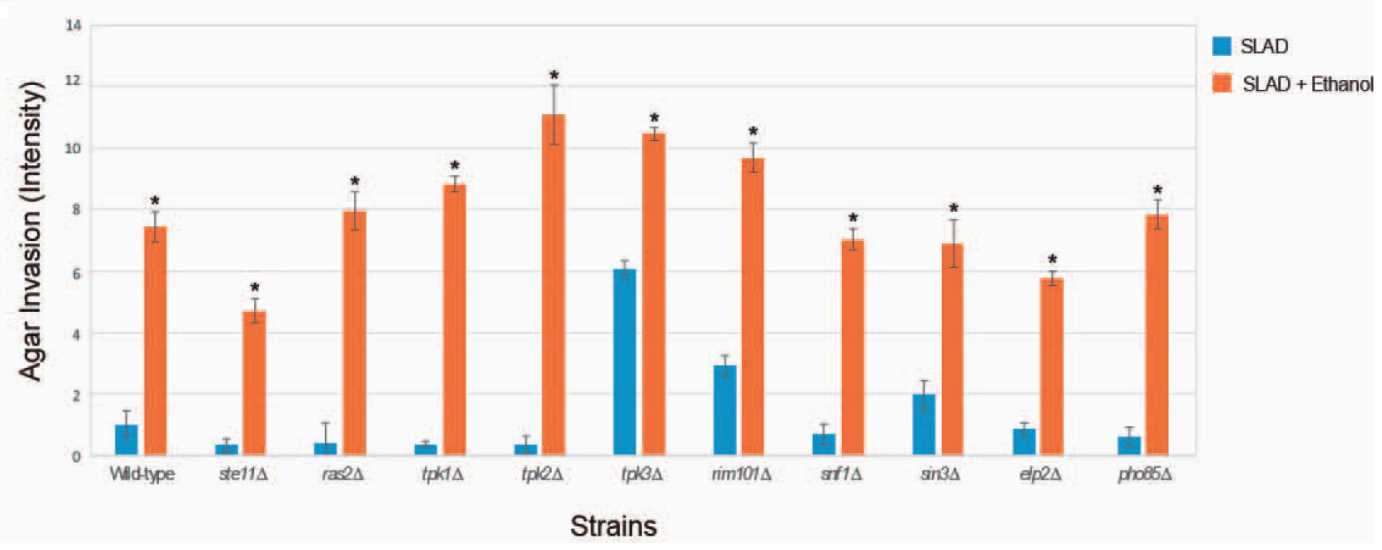

FIGURE 3 | Evaluating mutants lacking established filamentation regulatory pathways for ethanol-inducible invasion. (A) Wild-type cells (PC538, $\Sigma 1278 \mathrm{~b}$ MAT a haploid) and the indicated isogenic mutants were spotted onto nitrogen-limited medium (SLAD) with or without $2 \%$ ethanol (v/v). Plates were incubated for 4 days at $30^{\circ} \mathrm{C}$, photographed, washed in stream of water, and photographed again. Bar, $5 \mathrm{~mm}$. (B) Quantitation of invasive growth in panel (A) by densitometry, performed as described in the legend for Figure 1B. Cells were spotted in triplicate, and the average values are shown. Error bars represent the standard difference between experiments. Asterisk denotes a $p<0.01$ for samples relative to each strain's invasion in SLAD. (C) Colony peripheries from the plates in panel (A) were examined at 20X magnification. Bar, $50 \mu \mathrm{m}$. Arrows mark examples of pseudohyphae. 
invasive growth depending on growth on YPD or SLAD. This hypothesis is consistent with the fact that mutants scored for pseudohyphal and invasive growth do not completely overlap in a genome-wide screen (Ryan et al., 2012) and with the fact that several pathways, like Snflp, play different roles in response to carbon and nitrogen limitation (Orlova et al., 2010).

\section{Mitochondrial Retrograde Pathway is Required for Ethanol-Inducible Invasive Growth}

Other proteins and pathways regulate filamentous growth than those tested above (Ryan et al., 2012). A broader collection of genes implicated in filamentous growth regulation was examined. One of these is the mitochondrial retrograde pathway (or RTG pathway; Sekito et al., 2002; Liu et al., 2003; Liu and Butow, 2006; Kleine and Leister, 2016), which senses changes in metabolic respiration (Aun et al., 2013) to regulate filamentous growth. The RTG pathway has recently been shown to regulate the filamentation response to the alcohol butanol (Starovoytova et al., 2013). Rtg2p is a positive regulator of the retrograde pathway (Ferreira Junior et al., 2005). The rtg $2 \Delta$ mutant was defective for ethanol-dependent invasive growth (Figures $4 \mathrm{~A}-\mathrm{C}$ ). The RTG pathway is composed of two other regulators, the basic helixloop-helix leucine zipper transcription factors Rtg1p and Rtg3p, which hetero-dimerize to regulate transcription (Jia et al., 1997). The $r \operatorname{tg} 1 \Delta$ and $r \operatorname{tg} 3 \Delta$ mutants were also defective for ethanoldependent invasive growth (Figures 4A-C).

The RTG pathway controls expression of genes that function to ameliorate defects in mitochondrial function (Epstein et al., 2001). The activity of the RTG pathway can be assessed by examining the expression of the CIT2 gene, which is a target of the retrograde pathway (Liao and Butow, 1993; Chelstowska and Butow, 1995; Kos et al., 1995; Jia et al., 1997; Liu and Butow, 1999) that encodes peroxisome citrate synthase (Kim et al., 1986). Ethanol stimulated the activity of a CIT2-lacZ transcriptional reporter (Figure 4D) in a manner that was dependent on Rtg2p (Figure 4D). Interestingly, the data indicates that ethanol induces the RTG pathway. One possibility is that nitrogen and ethanol both activate the RTG pathway. The addition of ethanol to cells grown in nitrogen-limiting media showed an additional stimulation (Figure 4D). Thus, nitrogen limitation and ethanol both contribute to RTG pathway activity. Therefore, the mitochondrial retrograde pathway regulates ethanol-inducible filamentous growth.

\section{Mitochondrial Retrograde Pathway Regulates Ethanol-Inducible Filamentous Growth Independent of fMAPK, TOR, and HOG Pathways}

To define how the RTG pathway connects to the ethanol response, known regulators of that pathway were examined. Mks1p is a negative regulator of multiple pathways, including Rtg2p in the mitochondrial retrograde pathway (Dilova et al., 2004; Ferreira Junior et al., 2005). Mkslp was not required for invasive growth in response to ethanol (Figures $\mathbf{5 A - C}$ ), which indicates that another negative regulator of the pathway might function in this context. The RTG pathway can regulate the fMAPK pathway (Chavel et al., 2010), as part of a highly coordinated transcriptional sensing and signaling circuit among the pathways that regulate filamentous growth (Borneman et al., 2006; Bharucha et al., 2008; Chavel et al., 2014). We tested whether cells with an up-regulated RTG pathway functioned through fMAPK. An $m k s 1 \Delta$ ste $11 \Delta$ double mutant, which has an up-regulated retrograde pathway and lacks the MAPKKK for the fMAPK pathway (Ste11p), showed ethanol-inducible invasive growth. This result aligns with the abovementioned results that fMAPK does not regulate ethanol-dependent filamentous growth and indicates that the mitochondrial retrograde pathway does not control filamentation through fMAPK (Figures 5A,B). As shown above, the mks1 ste11 $\Delta$ double mutant did not show an increase in filamentation at colony peripheries (Figure 5C).

Another major regulator of the mitochondrial retrograde pathway is the TOR pathway, which is a ubiquitous nutrientregulatory pathway in eukaryotes (Bar-Peled and Sabatini, 2014). TOR plays an important role in nutrient-regulated responses in yeast (Heitman et al., 1991) and is a master regulator of nitrogen control (Beck and Hall, 1999; Cardenas et al., 1999; Bruckner et al., 2011; Kingsbury et al., 2015). TOR signaling also links nitrogen quality to the activity of the Rtglp and Rtg3p transcription factors (Komeili et al., 2000). TOR specifically regulates the expression of genes encoding RTG pathway components (Crespo et al., 2002; Dilova et al., 2004). We found that the TOR pathway was not required for ethanol-inducible filamentous growth (Figures 5A-C; tor $1 \Delta, \operatorname{tco} 89 \Delta$ ). In addition, the AGC-type kinase Sch9p, which is phosphorylated by and is a major target of TORC1, and which contributes to TORC1-mediated regulation of ribosome biogenesis (Urban et al., 2007; Wei and Zheng, 2009), was not required for ethanol-dependent invasion ( $\operatorname{sch} 9 \Delta$ Figures 5A,B, although it was required for filamentation at colony perimeters Figure $5 \mathrm{C}$ ). These results may not be entirely surprising, because although TOR and the mitochondrial retrograde pathway are functionally connected, the retrograde response to mitochondrial dysfunction is not dependent on TOR1-dependent regulation of retrograde gene expression (Giannattasio et al., 2005). Therefore, the mitochondrial retrograde pathway controls ethanol-inducible filamentous growth independent of TOR and at least partly independently of Sch9p.

In addition to TOR, the SAP- or p38-type high osmolarity glycerol response (HOG) MAP kinase pathway, which controls the response to osmotic and other stresses (Westfall et al., 2004; Saito, 2010), also regulates the RTG pathway (RuizRoig et al., 2012). The HOG pathway was not required for ethanol-inducible filamentous growth (Figures 5A-C, pbs $2 \Delta$ ). Another function of the RTG pathway is to stimulate peroxisome biogenesis in periods of mitochondrial stress (Liao and Butow, 1993; Chelstowska and Butow, 1995; Kos et al., 1995; Epstein et al., 2001). Peroxisomes, which control elements of metabolism and can be regulated by the RTG pathway (Chelstowska and Butow, 1995), may impact ethanol-dependent filamentous 
A

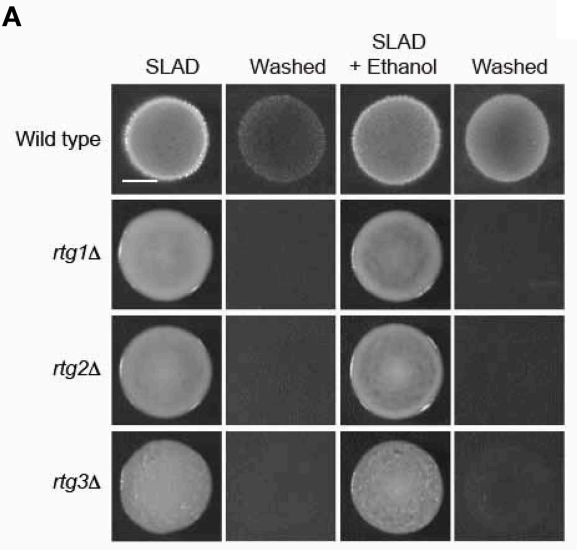

C

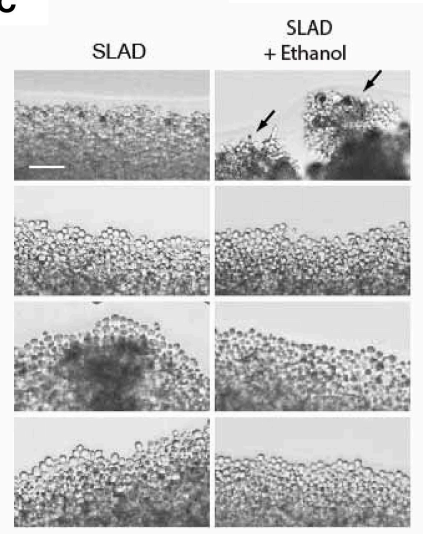

B

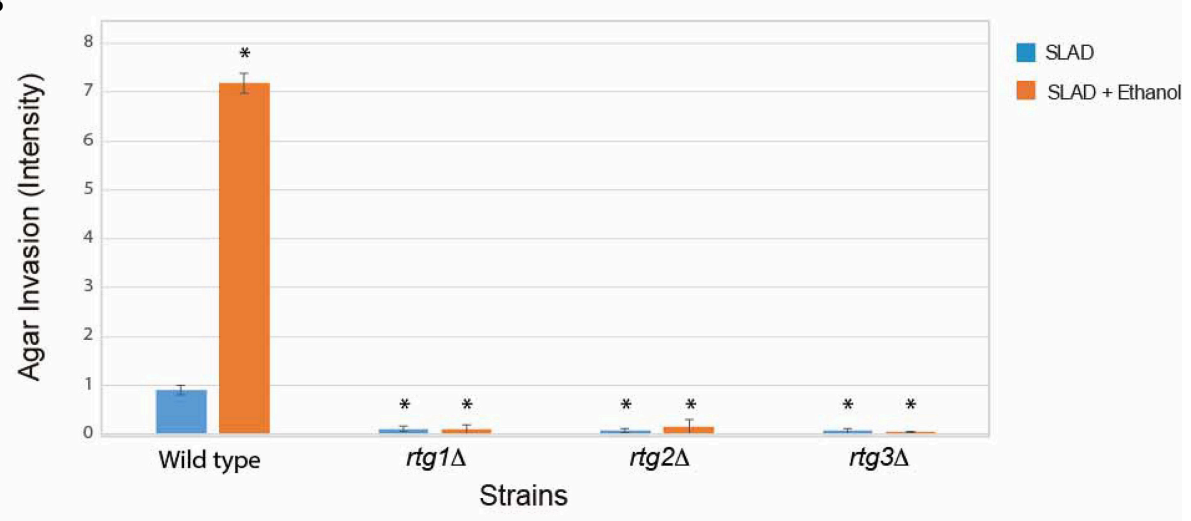

D

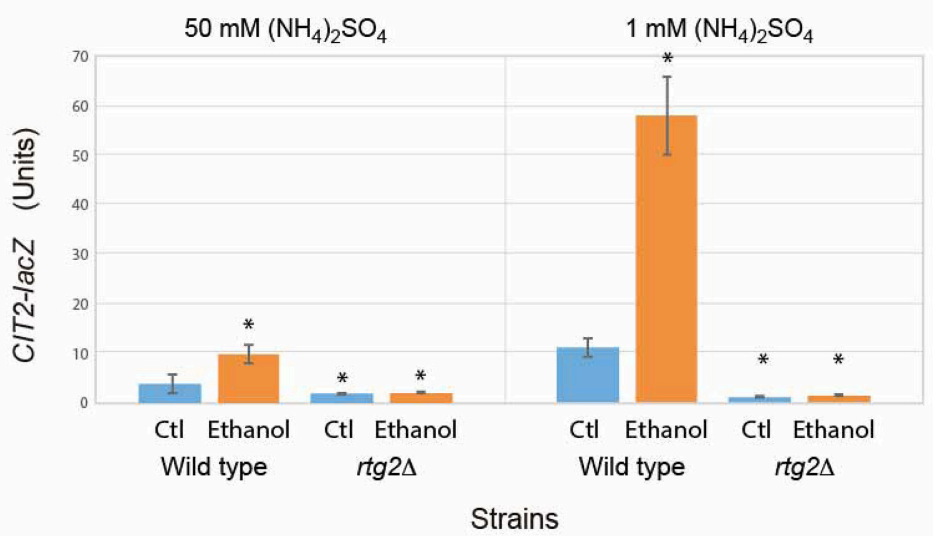

FIGURE 4 | Role of the RTG pathway in regulating ethanol-inducible invasive growth. (A) Wild-type cells (PC538, $1278 \mathrm{~b}$ MATa haploid) and the indicated isogenic mutants were spotted onto nitrogen limiting medium (SLAD) with or without $2 \%$ ethanol (V/v). Plates were incubated for 4 days at $30^{\circ} \mathrm{C}$, photographed, washed in stream of water, and photographed again. Bar, $5 \mathrm{~mm}$. (B) Quantitation of invasive growth in panel (A) by densitometry, performed as described in the legend for Figure 1B. Cells were spotted in triplicate, and the average values are shown. Error bars represent the standard difference between experiments. Asterisk denotes a $p<0.01$ for samples relative to wild type in SLAD. (C) Colony peripheries from the plates in panel (A) were examined by microscopy at 20X magnification. Bar, $50 \mu \mathrm{m}$. Arrows mark examples of pseudohyphae. (D) Beta-galactosidase activity of the ClT2-lacZ reporter in wild-type cells and the rtg2 $\Delta$ mutant grown in 1 or $50 \mathrm{mM}\left(\mathrm{NH}_{4}\right)_{2} \mathrm{SO}_{4}$ with or without 2\% ethanol $(\mathrm{V} / \mathrm{V})$. Experiments were performed in triplicate from independent inductions. Error bars represent the standard deviation between experiments. Asterisk denotes a $p<0.01$ for samples relative to wild type in media lacking ethanol (Ctl).

growth. A mutant lacking peroxisomes was not required for ethanol-dependent filamentous growth, indicating that this is not the case (Figures $5 \mathrm{~A}-\mathrm{C}$, pex3 $\Delta$ ). However, the pex3 $\Delta$ mutant did show some defect (Figure 5B), and Cit2p, which is a target of RTG, was induced by ethanol (Figure 4D). These proteins regulate the glyoxylate cycle (Jazwinski, 2013) and 
A

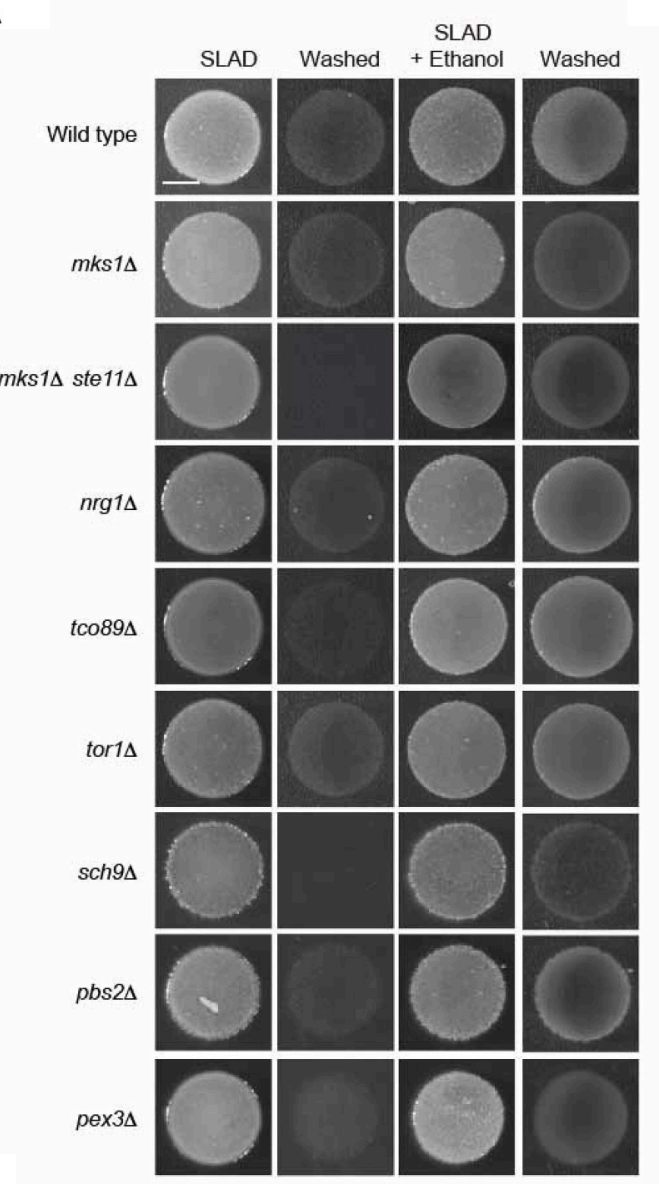

C

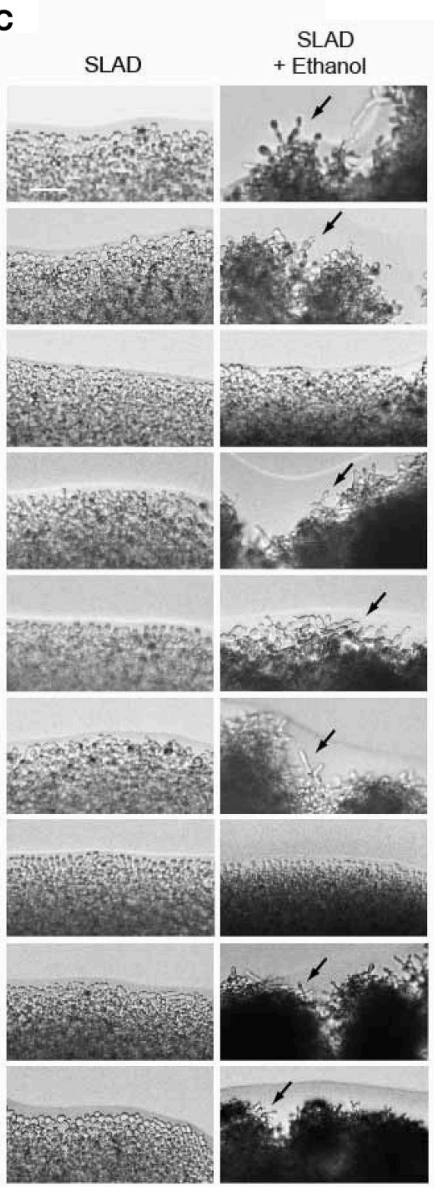

B

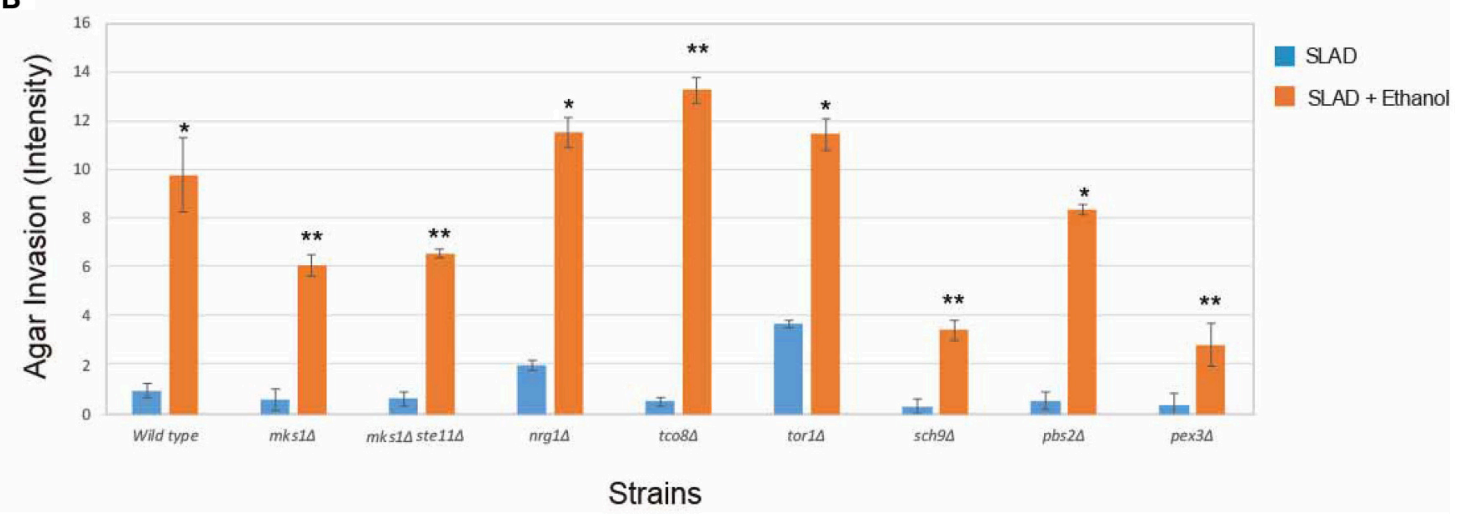

FIGURE 5 | Role of RTG pathway regulators in controlling ethanol-inducible invasive growth. (A) Wild-type cells (PC538, $\Sigma 1278 \mathrm{~b}$ MATa haploid) and the indicated isogenic mutants were spotted onto nitrogen-limiting medium (SLAD) with or without $2 \%$ ethanol (V/V). Plates were incubated for 4 days at $30^{\circ} \mathrm{C}$, photographed, washed in stream of water, and photographed again. Bar, $5 \mathrm{~mm}$. (B) Quantitation of invasive growth in panel (A) by densitometry, performed as described in the legend for Figure 1B. Cells were spotted in triplicate, and the average values are shown. Error bars represent the standard difference between experiments. Asterisk denotes a $p<0.01$ for samples relative to each strain's invasion in SLAD. Double asterisk refers to a $p<0.01$ for samples relative to each strain's invasion in SLAD compared to wild-type in SLAD with ethanol. (C) Colony peripheries from the plates in panel (A) were examined by microscopy at 20X magnification. Bar, $50 \mu \mathrm{m}$. Arrows mark examples of pseudohyphae.

it is possible that that metabolic pathway plays a role in regulating ethanol-inducible filamentous growth. Therefore, the mitochondrial retrograde pathway regulates ethanol-inducible filamentous growth in a manner that is separate from TOR, fMAPK, and HOG, and partly independent of peroxisome function. 


\section{Regulation of the TCA Cycle Underlies the Role of the Mitochondrial Retrograde Pathway in Controlling Ethanol-Inducible Filamentous Growth}

The tricarboxylic acid (TCA or citric acid/Krebs) cycle functions through a series of reactions to generate ATP and produce reducing agents necessary for mitochondrial electron transport and energy generation. The TCA cycle is compromised in cells experiencing mitochondrial defects, but flux through the pathway can be maintained by the action of the RTG pathway (Liu and Butow, 1999; Lin et al., 2011), which is a major function of the RTG pathway (Butow and Avadhani, 2004). Glutamate can suppress the requirement for the retrograde pathway in the TCA cycle by increasing metabolic flux (Liu and Butow, 1999). Glutamate suppressed the defect in ethanol-inducible filamentous growth of the $r \operatorname{tg} 1 \Delta, r \operatorname{tg} 2 \Delta$, and $r \operatorname{tg} 3 \Delta$ mutants (Figures $6 \mathrm{~A}-\mathrm{C}$ ). The role of the RTG pathway in regulating ethanol-inducible invasion suggests that mitochondrial respiration is important for ethanoldependent invasive growth. Consistent with this possibility, $r h o^{0}$ cells, which lack a functional mitochondria, were defective for ethanol-inducible invasive growth (Figures 6A-C). Thus, one function of the RTG pathway in ethanol-dependent filamentous growth is to stimulate flux through the TCA cycle. Glutamate did not suppress the invasive growth defect of the flo11 $\Delta$ mutant (Figures 6A-C). Given that Flo11p is the main cell adhesion molecule that regulates filamentous growth, these results suggest that glutamate-dependent invasive growth in $r$ tg mutants is mediated (in some manner) through Flo11p.

The mitochondrial retrograde pathway has also been shown to regulate deoxyribonucleotide pools by impacting the rate of threonine metabolism (Hartman, 2007). Hydroxyurea induces a cell-cycle delay (Adams and Lindsay, 1967) and reduces the rate of DNA synthesis (Niu et al., 2008), and accordingly triggers a filamentation-like response (Jiang and Kang, 2003). Ethanol may impact threonine levels and DNA synthesis rates and induce retrograde-dependent filamentation. However, hydroxyurea, unlike ethanol, did not cause invasive growth in SLAD medium (Figure S4B). Moreover, the elongated cell morphology induced by hydroxyurea was retrograde-independent (Figure S4C). Therefore, the mitochondrial retrograde pathway probably does not regulate ethanol-dependent filamentous growth by influencing the rate of threonine metabolism.

Several other mutants that are defective in pathways surrounding the TCA cycle, ethanol uptake and metabolism, signaling, and the cell cycle were examined for a role in ethanolinducible filamentous growth (Figure S5). Most of the mutants examined showed a detectable reduction in ethanol-inducible invasive growth (Figure S5). Two mutants stood out. One lacked Adh2p, which might be expected as that protein catalyzes the conversion of ethanol to acetaldehyde (Bennetzen and Hall, 1982; Young and Pilgrim, 1985; Dickinson et al., 2003). The other lacked Csf1p (Figure S5), a protein that is required for fermentation at low temperatures (Tokai et al., 2000). Notably, the wine yeast P24, which does not invade the agar in SLAD medium, is defective for growth at low temperatures (GarcíaRíos et al., 2014). Thus, the regulators of ethanol-inducible filamentous growth may encompass a more diverse collection of proteins than has been defined here.

\section{Ethanol-Inducible Filamentous Growth Requires the Polarisome and Occurs through Induction of FL011 Expression}

Filamentous growth involves at least three major regulatory changes. One is an increase in cell length, which is mediated by a delay in the cell cycle (Kron et al., 1994) and by an increase in polarized growth by a Cdc42p-dependent mechanism that involves the polarisome (Cullen and Sprague, 2002). The formin Bnilp (Evangelista et al., 1997) and accessory proteins Bud6p, Pea2p, and Spa2p comprise the polarisome (Amberg et al., 1997; Sagot et al., 2002; Graziano et al., 2011; Tu et al., 2012). Another change is a switch in polarity to distal-unipolar budding that requires the distal-pole landmark Bud8p (Gimeno et al., 1992; Cullen and Sprague, 2002). Bud8p is a distal-pole marker that localizes to the distal pole of the cell (Harkins et al., 2001). The third change, as discussed above, is an increase in adhesion mediated by the cell adhesion molecule Flo11p (Lambrechts et al., 1996; Lo and Dranginis, 1996; Guo et al., 2000). The different aspects of filamentous growth are genetically separable and can be examined by mutants that specifically compromise each aspect of the response (Cullen and Sprague, 2002). Mutants were examined that were specifically defective for polarized growth $(b u d 6 \Delta)$, polarity reorganization (bud8 $\Delta$ ), or cell adhesion $($ flo11 $\Delta)$. Ethanol-inducible filamentous growth occurred in cells lacking Bud8 (Figures 7A-C, bud8 $\Delta$ ), which indicates that ethanol does not function mainly through the switch in polarity. Ethanol-inducible filamentous growth was reduced in cells lacking the polarisome component Bud6p (Figures 7A-C, bud6 $\Delta$ ). Thus, ethanol induces filamentous growth by a mechanism that is partly dependent on the increase in polarized growth driven by the polarisome. This is consistent with studies of fusel alcohols, which induce dramatic changes in cell length (Dickinson, 1996; Lorenz et al., 2000). Ethanol-inducible filamentous growth was also dependent on Flo11p (Figures 7A-C, flo11 $\Delta$ ). Consistent with this result, ethanol stimulated the expression of the FLO11 gene (Figure 7D). Therefore, ethanol-inducible filamentous growth, which is controlled by the RTG pathway, requires polarisome function and occurs by a mechanism that involves Flo11pdependent transcriptional induction.

\section{DISCUSSION}

Filamentous growth in yeast has been mainly studied in one strain background ( $\sum 1278 b$; Gimeno et al., 1992), in part because most laboratory strains have lost filamentation properties due to genetic manipulation in the laboratory (Liu et al., 1996; Dowell et al., 2010; Chin et al., 2012). Although filamentous growth is common among "wild" S. cerevisiae strains (Carstens et al., 1998; Sidari et al., 2014), the triggers of filamentous growth have not been extensively characterized in other backgrounds. By 

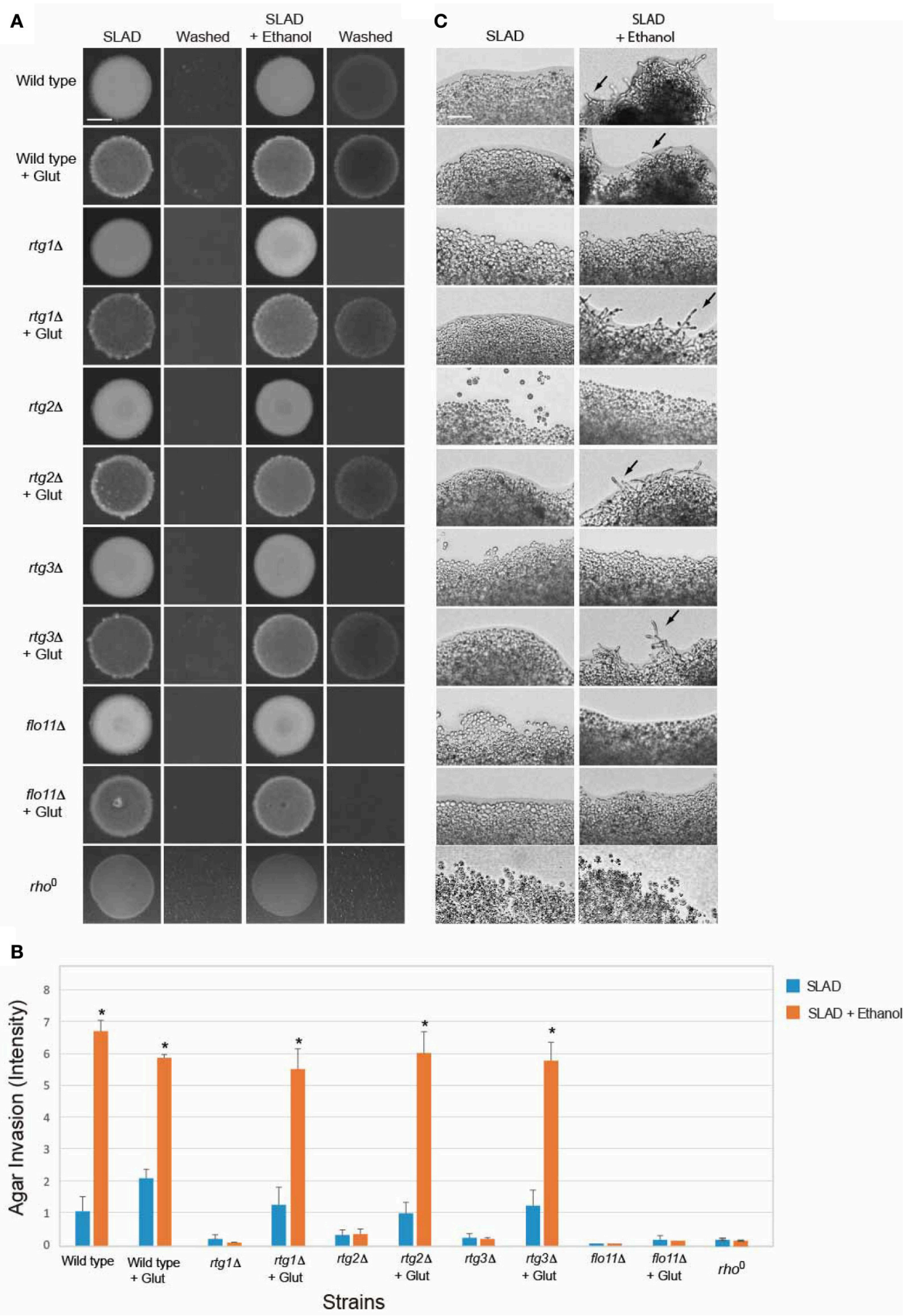

FIGURE 6 | Impact of glutamate on ethanol-inducible invasive growth defect of $\boldsymbol{r t g}$ mutants. (A) Wild-type cells (PC538, $\Sigma 1278 \mathrm{~b}$ MATa haploid) and the indicated isogenic mutants were spotted onto nitrogen limiting medium (SLAD) with or without $2 \%$ ethanol (v/v). Plates were incubated for 4 days at $30^{\circ} \mathrm{C}$, photographed, washed in stream of water, and photographed again. Bar, $5 \mathrm{~mm}$. Glutamate was added at a concentration of $200 \mu \mathrm{M}$. (B) Quantitation of invasive growth in panel (A) by densitometry. Cells were spotted in triplicate, and the average values are shown. Error bars represent the standard difference between experiments. Asterisk denotes a $p<0.05$ for samples relative to each strain's invasion in SLAD. (C) Colony peripheries from the plates in panel (A) were examined by microscopy at 20X magnification. Bar, $50 \mu \mathrm{m}$. Arrows mark examples of pseudohyphae. 

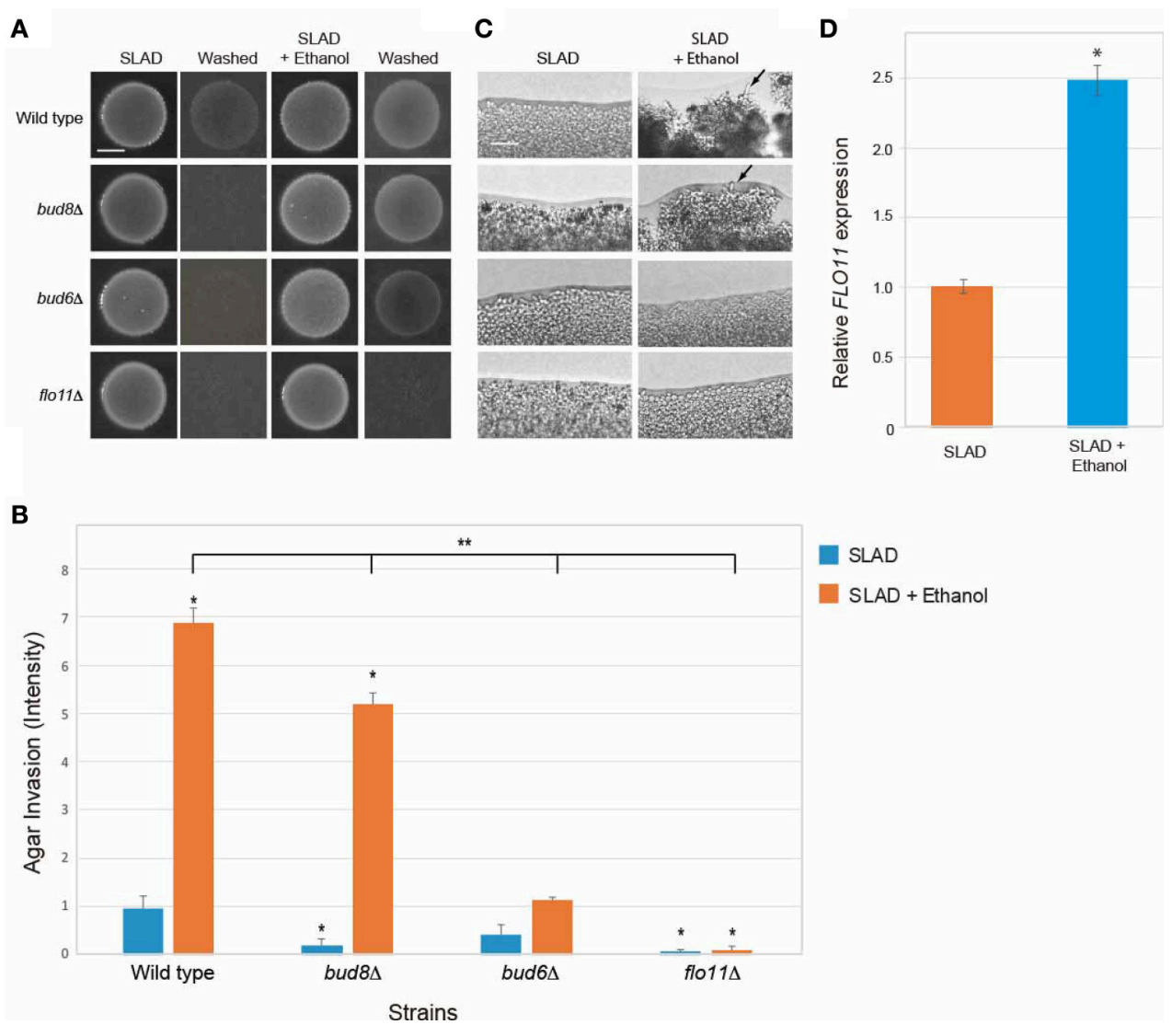

FIGURE 7 | Requirement for Bud8, Bud6, and Flo11 in mediating ethanol-inducible invasive growth. (A) Wild-type cells (PC538, $51278 \mathrm{~b}$ MATa haploid) and the indicated isogenic mutants were spotted onto nitrogen-limiting medium (SLAD) with or without ethanol $(2 \% \mathrm{v} / \mathrm{V})$. Plates were incubated for 4 days at $30^{\circ} \mathrm{C}$, photographed, washed in stream of water, and photographed again. Bar, $5 \mathrm{~mm}$. (B) Quantitation of invasive growth in panel (A) by densitometry, performed as described in the legend for Figure 1B. Asterisk denotes a $p<0.01$ for samples relative to wild type invasion in SLAD. Double asterisk denotes a $p<0.01$ for samples relative to wild type invasion in SLAD with ethanol. (C) Colony peripheries from the plates in panel (A) were examined by microscopy 20X magnification. Bar, $50 \mu \mathrm{m}$. (D) Ethanol stimulates FLO11 expression in SLAD medium. Cells were incubated in SLAD (orange bar) or SLAD with ethanol (blue bar). Gene expression was examined by qPCR at time 45 min and normalized to a control transcript (ACT1). Error bar represents standard difference between samples. Asterisk denotes a $p<0.01$.

examining a collection of wine yeast, we show that most wine strains undergo filamentous growth. The strains also showed a high degree of phenotypic variation. Phenotypic variation is common among individual strains (Dowell et al., 2010) and may not be surprising given that these strains have undergone selection based on flavor, cold-sensitivity, alcohol tolerance, and flocculation (Suzzi et al., 1984; Fleet, 2003; Borneman et al., 2011).

We show here that nitrogen limitation and carbon limitation induce filamentous growth in most strains. This is consistent with previous claims that nitrogen limitation (Gimeno and Fink, 1994) and carbon limitation (Cullen and Sprague, 2000) trigger the filamentation response. We also show that ethanol and fusel alcohols induce filamentous growth. Ethanol (Dickinson, 1994; Lorenz et al., 2000) and fusel alcohols (Dickinson, 1996; Chen and Fink, 2006) are known to stimulate filamentous growth. Fusel alcohols induced filamentous growth under nutrient-replete conditions, and ethanol stimulated filamentous growth under nitrogen-limiting conditions. Ethanol is a byproduct of glycolysis, whereas fusel alcohols are by-products of Ehrlich reactions. Thus, the two types of alcohols may provide information about different nutritional states. During alcoholic fermentation, $S$. cerevisiae produces ethanol when it has reached a maximum population density that corresponds with consumption of nitrogen (Beltran et al., 2005). Because nitrogen limitation is itself a trigger for filamentous growth, ethanol may be a coincidence detector of nitrogen levels and TCA compromise. Alternatively, glucose uptake correlates with the rate of the TCA cycle (Heyland et al., 2009). We also identify a potential role for the glyoxylate cycle in regulating ethanol-dependent filamentous growth. Thus, ethanol production may be a readout of nitrogen or glucose availability.

The cellular response to mitochondrial stress is important for biological responses in many systems. Generally speaking, cellular responses to mitochondrial disfunction have been implicated in cancer (Guha and Avadhani, 2013), aging (Friis et al., 2014; da Cunha et al., 2015; Jazwinski, 2015), development (Berkowitz et al., 2016), and inter-organellar homeostasis (Liu 
and Butow, 2006). Here, we show that the fungal-specific RTG pathway controls ethanol-inducible invasive growth in yeast. Lorenz and Heitman argued that the fMAPK pathway mediates the response to alcohols (Lorenz et al., 2000), and we show that it may play a minor role. Here we establish the RTG pathway as a key pathway in the response. How does the RTG pathway control ethanol-dependent filamentous growth without involving other major filamentation regulatory pathways? One possibility is that the RTG pathway is part of the sensing/signaling mechanism that controls the rate of flux through the TCA cycle (Liu and Butow, 1999; Lin et al., 2011). TCA cycle rate is dependent on carbon and nitrogen levels, which are key inducers of filamentous growth in yeast and other fungal species. Canonical metabolic regulatory pathways that control filamentous growth also control TCA cycle flux including Snf1 (Hedbacker and Carlson, 2008) and TOR (Komeili et al., 2000); thus, TCA cycle activity may be a nexus for monitoring nutritional health.

The connection between TCA cycle flux and filamentous growth may be relevant from the perspective of pathogenecity. TCA cycle flux has been connected to the evolution of pathogenicity in filamentous fungi (Hogan et al., 2015) and apicomplexan parasites (Oppenheim et al., 2014). TCA cycle reprogramming is becoming increasingly tied to developmental transitions in pathogens ranging from C. albicans (Askew et al., 2009; Guedouari et al., 2014; Grahl et al., 2015), to Plasmodium falciparum (Ke et al., 2015) to Yersinia pseudotuberculosis (Bucker et al., 2014). The boost in TCA cycle flux is critical for phagososomal escape of the bacterial pathogen Francisella (Ramond et al., 2014). Moreover, the fungal RTG pathway is responsible for evasion of programmed cell death in yeast cells growing on non-repressing carbon sources (Guaragnella et al., 2013). Both the RTG pathway and relief of carbon catabolite repression are required for programmed cell death resistance. Evasion of programmed cell

\section{REFERENCES}

Abdullah, U., and Cullen, P. J. (2009). The tRNA modification complex elongator regulates the Cdc42-dependent mitogen-activated protein kinase pathway that controls filamentous growth in yeast. Eukaryot. Cell 8, 1362-1372. doi: 10.1128/EC.00015-09

Adams, R. L., and Lindsay, J. G. (1967). Hydroxyurea reversal of inhibition and use as a cell-synchronizing agent. J. Biol. Chem. 242, 1314-1317.

Adhikari, H., and Cullen, P. J. (2014). Metabolic respiration induces AMPK- and Irelp-dependent activation of the p38-Type HOG MAPK Pathway. PLoS Genet. 10:e1004734. doi: 10.1371/journal.pgen.1004734

Adhikari, H., Vadaie, N., Chow, J., Caccamise, L. M., Chavel, C. A., Li. B., et al. (2015). Role of the unfolded protein response in regulating the mucindependent filamentous-growth mitogen-activated protein kinase pathway. Mol. Cell. Biol. 35, 1414-1432. doi: 10.1128/MCB.01501-14

Albuquerque, P., and Casadevall, A. (2012). Quorum sensing in fungi-a review. Med. Mycol. 50, 337-345. doi: 10.3109/13693786.2011.652201

Alper, H., Moxley, J., Nevoigt, E., Fink, G. R., and Stephanopoulos, G. (2006). Engineering yeast transcription machinery for improved ethanol tolerance and production. Science 314, 1565-1568. doi: 10.1126/science.1131969

Amberg, D. C., Zahner, J. E., Mulholland, J. W., Pringle, J. R., and Botstein, D. (1997). Aip3p/Bud6p, a yeast actin-interacting protein that is involved in death and filamentous growth may be two hallmarks that fungi must acquire to become pathogenic. Our study therefore connects TCA cycle flux, as regulated by the RTG pathway, to an aspect of filamentous growth. Perhaps TCA flux controls developmental and morphogenetic responses in other eukaryotic systems.

\section{AUTHOR CONTRIBUTIONS}

BG designed and performed experiments. GB designed experiments. AM designed experiments. MJT designed experiments. PC helped with experimental design and writing the paper.

\section{FUNDING}

PC is supported from grants from the NIH (GM098629 and DE022720). The work was supported by the Ministry of Economy and Competitiveness, Spain (Grant no. AGL2013-47300-C3). BG is grateful to the pre-doctoral fellowship from the University Rovira i Virgili and the Oenological Biotechnology research group for a mobility grant.

\section{ACKNOWLEDGMENTS}

Thanks to Charlie Boone for generously providing the MATa $\sum 1278 \mathrm{~b}$ deletion collection, and Zhengchang Liu for providing the $p$ CIT2-lacZ plasmid. Thanks to Javier Rodriguez for technical assistance.

\section{SUPPLEMENTARY MATERIAL}

The Supplementary Material for this article can be found online at: http://journal.frontiersin.org/article/10.3389/fphys. 2017.00148/full\#supplementary-material morphogenesis and the selection of bipolar budding sites. Mol. Biol. Cell 8, 729-753. doi: 10.1091/mbc.8.4.729

Argueso, J. L., Carazzolle, M. F., Mieczkowski, P. A., Duarte, F. M., Netto, O. V., Missawa, S. K., et al. (2009). Genome structure of a Saccharomyces cerevisiae strain widely used in bioethanol production. Genome Res. 19, 2258-2270. doi: 10.1101/gr.091777.109

Askew, C., Sellam, A., Epp, E., Hogues, H., Mullick, A., Nantel, A. et al. (2009). Transcriptional regulation of carbohydrate metabolism in the human pathogen Candida albicans. PLoS Pathog. 5:e1000612. doi: 10.1371/journal.ppat. 1000612

Aun, A., Tamm, T., and Sedman, J. (2013). Dysfunctional mitochondria modulate cAMP-PKA signaling and filamentous and invasive growth of Saccharomyces cerevisiae. Genetics 193, 467-481. doi: 10.1534/genetics.112. 147389

Avbelj, M., Zupan, J., Kranjc, L., and Raspor, P. (2015). Quorum-sensing kinetics in Saccharomyces cerevisiae: a symphony of ARO genes and aromatic alcohols. J. Agric. Food Chem. 63, 8544-8550. doi: 10.1021/acs.jafc.5b03400

Bar-Peled, L., and Sabatini, D. M. (2014). Regulation of mTORC1 by amino acids. Trends Cell Biol. 24, 400-406. doi: 10.1016/j.tcb.2014.03.003

Barrales, R. R., Jimenez, J., and Ibeas, J. I. (2008). Identification of novel activation mechanisms for FLO11 regulation in Saccharomyces cerevisiae. Genetics 178, 145-156. doi: 10.1534/genetics.107.081315 
Beck, T., and Hall, M. N. (1999). The TOR signalling pathway controls nuclear localization of nutrient- regulated transcription factors. Nature 402, 689-692. doi: $10.1038 / 45287$

Beltran, G., Esteve-Zarzoso, B., Rozes, N., Mas, A., and Guillamon, J. M. (2005). Influence of the timing of nitrogen additions during synthetic grape must fermentations on fermentation kinetics and nitrogen consumption. J. Agric. Food Chem. 53, 996-1002. doi: 10.1021/jf0487001

Beltran, G., Novo, M., Guillamon, J. M., Mas, A., and Rozes, N. (2008). Effect of fermentation temperature and culture media on the yeast lipid composition and wine volatile compounds. Int. J. Food Microbiol. 121, 169-177. doi: $10.1016 /$ j.ijfoodmicro.2007.11.030

Beltran, G., Novo, M., Rozes, N., Mas, A., and Guillamon, J. M. (2004). Nitrogen catabolite repression in Saccharomyces cerevisiae during wine fermentations. FEMS Yeast Res. 4, 625-632. doi: 10.1016/j.femsyr.2003.12.004

Bennetzen, J. L., and Hall, B. D. (1982). The primary structure of the Saccharomyces cerevisiae gene for alcohol dehydrogenase. J. Biol. Chem. 257, 3018-3025.

Berkowitz, O., De Clercq, I., Van Breusegem, F., and Whelan, J. (2016). Interaction between hormonal and mitochondrial signalling during growth, development and in plant defence responses. Plant Cell Environ. 39, 1127-1139. doi: $10.1111 /$ pce. 12712

Bharucha, N., Ma, J., Dobry, C. J., Lawson, S. K., Yang, Z., and Kumar, A. (2008). Analysis of the yeast kinome reveals a network of regulated protein localization during filamentous growth. Mol. Biol. Cell 19, 2708-2717. doi: 10.1091/mbc.E07-11-1199

Bojsen, R. K., Andersen, K. S., and Regenberg, B. (2012). Saccharomyces cerevisiae-a model to uncover molecular mechanisms for yeast biofilm biology. FEMS Immunol. Med. Microbiol. 65, 169-182. doi: 10.1111/j.1574-695X.2012. 00943.x

Borneman, A. R., Desany, B. A., Riches, D., Affourtit, J. P., Forgan, A. H., Pretorius, I. S., et al. (2011). Whole-genome comparison reveals novel genetic elements that characterize the genome of industrial strains of Saccharomyces cerevisiae. PLoS Genet. 7:e1001287. doi: 10.1371/journal.pgen.1001287

Borneman, A. R., Desany, B. A., Riches, D., Affourtit, J. P., Forgan, A. H., Pretorius, I. S., et al. (2012). The genome sequence of the wine yeast VIN7 reveals an allotriploid hybrid genome with Saccharomyces cerevisiae and Saccharomyces kudriavzevii origins. FEMS Yeast Res. 12, 88-96. doi: 10.1111/j.1567-1364.2011.00773.x

Borneman, A. R., Forgan, A. H., Pretorius, I. S., and Chambers, P. J. (2008). Comparative genome analysis of a Saccharomyces cerevisiae wine strain. FEMS Yeast Res. 8, 1185-1195. doi: 10.1111/j.1567-1364.2008.00434.x

Borneman, A. R., Leigh-Bell, J. A., Yu, H., Bertone, P., Gerstein, M., and Snyder, M. (2006). Target hub proteins serve as master regulators of development in yeast. Genes Dev. 20, 435-448. doi: 10.1101/gad.1389306

Borneman, A. R., and Pretorius, I. S. (2015). Genomic insights into the Saccharomyces sensu stricto complex. Genetics 199, 281-291. doi: 10.1534/genetics.114.173633

Bruckner, S., Kern, S., Birke, R., Saugar, I., Ulrich, H. D., and Mösch, H. U. (2011). The TEA transcription factor Tecl links TOR and MAPK pathways to coordinate yeast development. Genetics 189, 479-494. doi: 10.1534/genetics.111.133629

Bucker, R., Heroven, A. K., Becker, J., Dersch, P., and Wittmann, C. (2014). The pyruvate-tricarboxylic acid cycle node: a focal point of virulence control in the enteric pathogen Yersinia pseudotuberculosis. J. Biol. Chem. 289, 30114-30132. doi: 10.1074/jbc.M114.581348

Butow, R. A., and Avadhani, N. G. (2004). Mitochondrial signaling: the retrograde response. Mol. Cell 14, 1-15. doi: 10.1016/S1097-2765(04)00179-0

Cardenas, M. E., Cutler, N. S., Lorenz, M. C., Di Como, C. J., and Heitman, J. (1999). The TOR signaling cascade regulates gene expression in response to nutrients. Genes Dev. 13, 3271-3279. doi: 10.1101/gad.13.24.3271

Carrozza, M. J., Florens, L., Swanson, S. K., Shia, W. J., Anderson, S., Yates, J., et al. (2005). Stable incorporation of sequence specific repressors Ash1 and Ume6 into the Rpd3L complex. Biochim. Biophys. Acta 1731, 77-87. doi: 10.1016/j.bbaexp.2005.09.005

Carstens, E., Lambrechts, M. G., and Pretorius, I. S. (1998). Flocculation, pseudohyphal development and invasive growth in commercial wine yeast strains. S. Afr. J. Enol. Vitc. 19, 52-61.
Celenza, J. L., and Carlson, M. (1989). Mutational analysis of the Saccharomyces cerevisiae SNF1 protein kinase and evidence for functional interaction with the SNF4 protein. Mol. Cell. Biol. 9, 5034-5044. doi: 10.1128/MCB.9.11. 5034

Chavel, C. A., Caccamise, L. M., Li, B., and Cullen, P. J. (2014). Global regulation of a differentiation MAPK pathway in yeast. Genetics 198, 1309-1328. doi: 10.1534 /genetics.114.168252

Chavel, C. A., Dionne, H. M., Birkaya, B., Joshi, J., and Cullen, P. J. (2010). Multiple signals converge on a differentiation MAPK pathway. PLoS Genet. 6:e1000883. doi: 10.1371/journal.pgen.1000883

Chelstowska, A., and Butow, R. A. (1995). RTG genes in yeast that function in communication between mitochondria and the nucleus are also required for expression of genes encoding peroxisomal proteins. J. Biol. Chem. 270, 18141-18146. doi: 10.1074/jbc.270.30.18141

Chen, H., and Fink, G. R. (2006). Feedback control of morphogenesis in fungi by aromatic alcohols. Genes Dev. 20, 1150-1161. doi: 10.1101/gad.1411806

Chen, H., Fujita, M., Feng, Q., Clardy, J., and Fink, G. R. (2004). Tyrosol is a quorum-sensing molecule in Candida albicans. Proc. Natl. Acad. Sci. U.S.A. 101, 5048-5052. doi: 10.1073/pnas.0401416101

Chin, B. L., Ryan, O., Lewitter, F., Boone, C., and Fink, G. R. (2012). Genetic variation in Saccharomyces cerevisiae: circuit diversification in a signal transduction network. Genetics 192, 1523-1532. doi: 10.1534/genetics.112.145573

Colombo, S., Ma, P., Cauwenberg, L., Winderickx, J., Crauwels, M., Teunissen, A., et al. (1998). Involvement of distinct G-proteins, Gpa2 and Ras, in glucose- and intracellular acidification-induced cAMP signalling in the yeast Saccharomyces cerevisiae. EMBO J. 17, 3326-3341. doi: 10.1093/emboj/17.12.3326

Crespo, J. L., Powers, T., Fowler, B., and Hall, M. N. (2002). The TOR-controlled transcription activators GLN3, RTG1, and RTG3 are regulated in response to intracellular levels of glutamine. Proc. Natl. Acad. Sci. U.S.A. 99, 6784-6789. doi: 10.1073/pnas.102687599

Cullen, P. J., Sabbagh, W., Jr., Graham, E., Irick, M. M., van Olden, E. K., Neal, C., et al. (2004). A signaling mucin at the head of the Cdc42- and MAPKdependent filamentous growth pathway in yeast. Genes Dev. 18, 1695-1708. doi: 10.1101/gad.1178604

Cullen, P. J., and Sprague, G. F. Jr. (2000). Glucose depletion causes haploid invasive growth in yeast. Proc. Natl. Acad. Sci. U.S.A. 97, 13619-13624. doi: $10.1073 /$ pnas.240345197

Cullen, P. J., and Sprague, G. F. Jr. (2002). The roles of bud-site-selection proteins during haploid invasive growth in yeast. Mol. Biol. Cell 13, 2990-3004. doi: 10.1091/mbc.E02-03-0151

da Cunha, F. M., Torelli, N. Q., and Kowaltowski, A. J. (2015). Mitochondrial retrograde signaling: triggers, pathways, and outcomes. Oxid. Med. Cell. Longev. 2015:482582. doi: 10.1155/2015/482582

Dickinson, J. R. (1994). Irreversible formation of pseudohyphae by haploid Saccharomyces cerevisiae. FEMS Microbiol. Lett. 119, 99-103. doi: 10.1111/j.1574-6968.1994.tb06874.x

Dickinson, J. R. (1996). "Fusel" alcohols induce hyphal-like extensions and pseudohyphal formation in yeasts. Microbiology 142(Pt 6), 1391-1397. doi: 10.1099/13500872-142-6-1391

Dickinson, J. R., Salgado, L. E., and Hewlins, M. J. (2003). The catabolism of amino acids to long chain and complex alcohols in Saccharomyces cerevisiae. J. Biol. Chem. 278, 8028-8034. doi: 10.1074/jbc.M211914200

Dilova, I., Aronova, S., Chen, J. C., and Powers, T. (2004). Tor signaling and nutrient-based signals converge on Mkslp phosphorylation to regulate expression of Rtg1.Rtg3p-dependent target genes. J. Biol. Chem. 279, 46527-46535. doi: 10.1074/jbc.M409012200

Dowell, R. D., Ryan, O., Jansen, A., Cheung, D., Agarwala, S., Danford, T., et al. (2010). Genotype to phenotype: a complex problem. Science 328, 469. doi: $10.1126 /$ science.1189015

Epstein, C. B., Waddle, J. A., Hale, W. IV. Davé, V., Thornton, J., et al. (2001). Genome-wide responses to mitochondrial dysfunction. Mol. Biol. Cell 12, 297-308. doi: 10.1091/mbc.12.2.297

Evangelista, M., Blundell, K., Longtine, M. S., Chow, C. J., Adames, N., Pringle, J. R., et al. (1997). Bnilp, a yeast formin linking cdc42p and the actin cytoskeleton during polarized morphogenesis. Science 276, 118-122. doi: 10.1126/science.276.5309.118 
Ferreira Junior, J. R., Spirek, M., Liu, Z., and Butow, R. A. (2005). Interaction between Rtg2p and Mks1p in the regulation of the RTG pathway of Saccharomyces cerevisiae. Gene 354, 2-8. doi: 10.1016/j.gene.2005.03.048

Fleet, G. H. (2003). Yeast interactions and wine flavour. Int. J. Food Microbiol. 86, 11-22. doi: 10.1016/S0168-1605(03)00245-9

Fleet, G. H., and Heard G. M. (1993). "Yeasts: growth during fermentation," in Wine Microbiology and Biotechnology, ed. G. H. Fleet (Chur: Hardwood Academic Publishers), 27-54.

Friis, R. M., Glaves, J. P., Huan, T., Li, L., Sykes, B. D., and Schultz, M. C. (2014). Rewiring AMPK and mitochondrial retrograde signaling for metabolic control of aging and histone acetylation in respiratory-defective cells. Cell Rep. 7, 565-574. doi: 10.1016/j.celrep.2014.03.029

García-Ríos, E., López-Malo, M., and Guillamón, J. M. (2014). Global phenotypic and genomic comparison of two Saccharomyces cerevisiae wine strains reveals a novel role of the sulfur assimilation pathway in adaptation at low temperature fermentations. BMC Genomics 15:1059. doi: 10.1186/1471-2164-15-1059

Ghosh, S., Kebaara, B. W., Atkin, A. L., and Nickerson, K. W. (2008). Regulation of aromatic alcohol production in Candida albicans. Appl. Environ. Microbiol. 74, 7211-7218. doi: 10.1128/AEM.01614-08

Giannattasio, S., Liu, Z., Thornton, J., and Butow, R. A. (2005). Retrograde response to mitochondrial dysfunction is separable from TOR $1 / 2$ regulation of retrograde gene expression. J. Biol. Chem. 280, 42528-42535. doi: 10.1074/jbc.M509187200

Gimeno, C. J., and Fink, G. R. (1994). Induction of pseudohyphal growth by overexpression of PHD1, a Saccharomyces cerevisiae gene related to transcriptional regulators of fungal development. Mol. Cell. Biol. 14, 2100-2112. doi: 10.1128/MCB.14.3.2100

Gimeno, C. J., Ljungdahl, P. O., Styles, C. A., and Fink, G. R. (1992). Unipolar cell divisions in the yeast $S$. cerevisiae lead to filamentous growth: regulation by starvation and RAS. Cell 68, 1077-1090. doi: 10.1016/0092-8674(92) 90079-R

Goffeau, A., Barrell, B. G., Bussey, H., Davis, R. W., Dujon, B., Feldmann, H., et al. (1996). Life with 6000 genes. Science 274, 546, 563-547. doi: $10.1126 /$ science. 274.5287 .546

Goldstein, A. L., and McCusker, J. H. (1999). Three new dominant drug resistance cassettes for gene disruption in Saccharomyces cerevisiae. Yeast 15, 1541-1553.

Grahl, N., Demers, E. G., Lindsay, A. K., Harty, C. E., Willger, S. D., Piispanen, A. E., et al. (2015). Mitochondrial activity and Cyr1 are key regulators of Ras1 activation of C. albicans virulence pathways. PLoS Pathog 11:e1005133. doi: 10.1371/journal.ppat.1005133

Graziano, B. R., DuPage, A. G., Michelot, A., Breitsprecher, D., Moseley, J. B., Sagot, I., et al. (2011). Mechanism and cellular function of Bud6 as an actin nucleation-promoting factor. Mol. Biol. Cell 22, 4016-4028. doi: 10.1091/mbc.E11-05-0404

Guaragnella, N., Zdralevic, M., Lattanzio, P., Marzulli, D., Pracheil, T., Liu, Z., et al. (2013). Yeast growth in raffinose results in resistance to aceticacid induced programmed cell death mostly due to the activation of the mitochondrial retrograde pathway. Biochim. Biophys. Acta 1833, 2765-2774. doi: 10.1016/j.bbamcr.2013.07.017

Guedouari, H., Gergondey, R., Bourdais, A., Vanparis, O., Bulteau, A. L., Camadro, J. M., et al. (2014). Changes in glutathione-dependent redox status and mitochondrial energetic strategies are part of the adaptive response during the filamentation process in Candida albicans. Biochim. Biophys. Acta 1842, 1855-1869. doi: 10.1016/j.bbadis.2014.07.006

Guha, M., and Avadhani, N. G. (2013). Mitochondrial retrograde signaling at the crossroads of tumor bioenergetics, genetics and epigenetics. Mitochondrion 13, 577-591. doi: 10.1016/j.mito.2013.08.007

Guo, B., Styles, C. A., Feng, Q., and Fink, G. R. (2000). A Saccharomyces gene family involved in invasive growth, cell-cell adhesion, and mating. Proc. Natl. Acad. Sci. U.S.A. 97, 12158-12163. doi: 10.1073/pnas.2204 20397

Harkins, H. A., Page, N., Schenkman, L. R., De Virgilio, C., Shaw, S., et al. (2001). Bud8p and Bud9p, proteins that may mark the sites for bipolar budding in yeast. Mol. Biol. Cell 12, 2497-2518. doi: 10.1091/mbc.12.8.2497

Hartman, J. L. T. (2007). Buffering of deoxyribonucleotide pool homeostasis by threonine metabolism. Proc. Natl. Acad. Sci. U.S.A. 104, 11700-11705. doi: 10.1073/pnas.0705212104
Hazelwood, L. A., Daran, J. M., van Maris, A. J., Pronk, J. T., and Dickinson, J. R. (2008). The Ehrlich pathway for fusel alcohol production: a century of research on Saccharomyces cerevisiae metabolism. Appl. Environ. Microbiol. 74, 2259-2266. doi: 10.1128/AEM.02625-07

Hedbacker, K., and Carlson, M. (2008). SNF1/AMPK pathways in yeast. Front. Biosci. 13, 2408-2420. doi: 10.2741/2854

Heitman, J., Movva, N. R., and Hall, M. N. (1991). Targets for cell cycle arrest by the immunosuppressant rapamycin in yeast. Science 253, 905-909. doi: $10.1126 /$ science. 1715094

Heyland, J., Fu, J., and Blank, L. M. (2009). Correlation between TCA cycle flux and glucose uptake rate during respiro-fermentative growth of Saccharomyces cerevisiae. Microbiology 155, 3827-3837. doi: 10.1099/mic.0.030213-0

Hlavacek, O., Kucerova, H., Harant, K., Palkova, Z., and Vachova, L. (2009). Putative role for $\mathrm{ABC}$ multidrug exporters in yeast quorum sensing. FEBS Lett. 583, 1107-1113. doi: 10.1016/j.febslet.2009.02.030

Hogan, G. J., Brown, P. O., and Herschlag, D. (2015). Evolutionary Conservation and diversification of Puf RNA binding proteins and their mRNA targets. PLoS Biol. 13:e1002307. doi: 10.1371/journal.pbio.1002307

Huang, D., Friesen, H., and Andrews, B. (2007). Pho85, a multifunctional cyclindependent protein kinase in budding yeast. Mol. Microbiol. 66, 303-314. doi: 10.1111/j.1365-2958.2007.05914.x

Huang, D., Moffat, J., and Andrews, B. (2002). Dissection of a complex phenotype by functional genomics reveals roles for the yeast cyclin-dependent protein kinase Pho85 in stress adaptation and cell integrity. Mol. Cell. Biol. 22, 5076-5088. doi: 10.1128/MCB.22.14.5076-5088.2002

Jazwinski, S. M. (2013). The retrograde response: when mitochondrial quality control is not enough. Biochim. Biophys. Acta 1833, 400-409. doi: 10.1016/j.bbamcr.2012.02.010

Jazwinski, S. M. (2015). Mitochondria to nucleus signaling and the role of ceramide in its integration into the suite of cell quality control processes during aging. Ageing Res. Rev. 23, 67-74. doi: 10.1016/j.arr.2014.12.007

Jia, Y., Rothermel, B., Thornton, J., and Butow, R. A. (1997). A basic helix-loophelix-leucine zipper transcription complex in yeast functions in a signaling pathway from mitochondria to the nucleus. Mol. Cell. Biol. 17, 1110-1117. doi: 10.1128/MCB.17.3.1110

Jiang, Y. W., and Kang, C. M. (2003). Induction of S. cerevisiae filamentous differentiation by slowed DNA synthesis involves Mec1, Rad53 and Swel checkpoint proteins. Mol. Biol. Cell 14, 5116-5124. doi: 10.1091/mbc.E03-06-0375

Jin, R., Dobry, C. J., McCown, P. J., and Kumar, A. (2008). Large-scale analysis of yeast filamentous growth by systematic gene disruption and overexpression. Mol. Biol. Cell 19, 284-296. doi: 10.1091/mbc.E07-05-0519

Karunanithi, S., and Cullen, P. J. (2012). The filamentous growth MAPK pathway responds to glucose starvation through the Mig1/2 transcriptional repressors in Saccharomyces cerevisiae. Genetics 192, 869-887. doi: 10.1534/genetics.112.142661

Ke, H., Lewis, I. A., Morrisey, J. M., McLean, K. J., Ganesan, S. M., Painter, H. J., et al. (2015). Genetic investigation of tricarboxylic acid metabolism during the Plasmodium falciparum life cycle. Cell Rep. 11, 164-174. doi: 10.1016/j.celrep.2015.03.011

Kim, K. S., Rosenkrantz, M. S., and Guarente, L. (1986). Saccharomyces cerevisiae contains two functional citrate synthase genes. Mol. Cell. Biol. 6, 1936-1942. doi: 10.1128/MCB.6.6.1936

Kingsbury, J. M., Sen, N. D., and Cardenas, M. E. (2015). Branched-Chain Aminotransferases Control TORC1 Signaling in Saccharomyces cerevisiae. PLoS Genet. 11:e1005714. doi: 10.1371/journal.pgen.1005714

Kleine, T., and Leister, D. (2016). Retrograde signaling: organelles go networking. Biochim. Biophys. Acta 1857, 1313-1325. doi: 10.1016/j.bbabio.2016.03.017

Komeili, A., Wedaman, K. P., O'Shea, E. K., and Powers, T. (2000). Mechanism of metabolic control. Target of rapamycin signaling links nitrogen quality to the activity of the Rtg1 and Rtg3 transcription factors. J. Cell Biol. 151, 863-878. doi: $10.1083 /$ jcb.151.4.863

Kos, W., Kal, A. J., van Wilpe, S., and Tabak, H. F. (1995). Expression of genes encoding peroxisomal proteins in Saccharomyces cerevisiae is regulated by different circuits of transcriptional control. Biochim. Biophys. Acta 1264, 79-86. doi: 10.1016/0167-4781(95)00127-3

Krogan, N. J., and Greenblatt, J. F. (2001). Characterization of a six-subunit Holo-Elongator complex required for the regulated expression of a group 
of genes in Saccharomyces cerevisiae. Mol. Cell. Biol. 21, 8203-8212. doi: 10.1128/MCB.21.23.8203-8212.2001

Kron, S. J., Styles, C. A., and Fink, G. R. (1994). Symmetric cell division in pseudohyphae of the yeast Saccharomyces cerevisiae. Mol. Biol. Cell 5, 1003-1022. doi: 10.1091/mbc.5.9.1003

Kruppa, M. (2008). Quorum sensing and Candida albicans. Mycoses. 52, 1-10. doi: 10.1111/j.1439-0507.2008.01626.x

Kuchin, S., Vyas, V. K., and Carlson, M. (2002). Snf1 protein kinase and the repressors Nrg1 and Nrg2 regulate FLO11, haploid invasive growth, and diploid pseudohyphal differentiation. Mol. Cell. Biol. 22, 3994-4000. doi: 10.1128/MCB.22.12.3994-4000.2002

Lamb, T. M., and Mitchell, A. P. (2003). The transcription factor Rim101p governs ion tolerance and cell differentiation by direct repression of the regulatory genes NRG1 and SMP1 in Saccharomyces cerevisiae. Mol. Cell. Biol. 23, 677-686. doi: 10.1128/MCB.23.2.677-686.2003

Lamb, T. M., Xu, W., Diamond, A., and Mitchell, A. P. (2001). Alkaline response genes of Saccharomyces cerevisiae and their relationship to the RIM101 pathway. J. Biol. Chem. 276, 1850-1856. doi: 10.1074/jbc.M008381200

Lambrechts, M. G., Bauer, F. F., Marmur, J., and Pretorius, I. S. (1996). Muc1, a mucin-like protein that is regulated by Mss10, is critical for pseudohyphal differentiation in yeast. Proc. Natl. Acad. Sci. U.S.A. 93, 8419-8424. doi: 10.1073/pnas.93.16.8419

Langford, M. L., Hargarten, J. C., Patefield, K. D., Marta, E., Blankenship, J. R., Fanning, S., et al. (2013). Candida albicans Czf1 and Efg1 coordinate the response to farnesol during quorum sensing, whiteopaque thermal dimorphism, and cell death. Eukaryot. Cell 12, 1281-1292. doi: 10.1128/EC.00311-12

Lengeler, K. B., Davidson, R. C., D’Souza, C., Harashima, T., Shen, W. C., Wang, P., et al. (2000). Signal transduction cascades regulating fungal development and virulence. Microbiol. Mol. Biol. Rev. 64, 746-785. doi: 10.1128/MMBR.64.4.746-785.2000

Lesage, P., Yang, X., and Carlson, M. (1996). Yeast SNF1 protein kinase interacts with SIP4, a C6 zinc cluster transcriptional activator: a new role for SNF1 in the glucose response. Mol. Cell. Biol. 16, 1921-1928. doi: 10.1128/MCB.16.5.1921

Li, L., Wright, S. J., Krystofova, S., Park, G., and Borkovich, K. A. (2007). Heterotrimeric $\mathrm{G}$ protein signaling in filamentous fungi. Annu. Rev. Microbiol. 61, 423-452. doi: 10.1146/annurev.micro.61.080706.093432

Liao, X., and Butow, R. A. (1993). RTG1 and RTG2: two yeast genes required for a novel path of communication from mitochondria to the nucleus. Cell 72, 61-71. doi: 10.1016/0092-8674(93)90050-Z

Lin, A. P., Anderson, S. L., Minard, K. I., and McAlister-Henn, L. (2011). Effects of excess succinate and retrograde control of metabolite accumulation in yeast tricarboxylic cycle mutants. J. Biol. Chem. 286, 33737-33746. doi: 10.1074/jbc.M111.266890

Liti, G., Carter, D. M., Moses, A. M., Warringer, J., Parts, L., James, S. A., et al. (2009). Population genomics of domestic and wild yeasts. Nature 458, 337-341. doi: $10.1038 /$ nature 07743

Liu, H., Styles, C. A., and Fink, G. R. (1993). Elements of the yeast pheromone response pathway required for filamentous growth of diploids. Science 262, 1741-1744.

Liu, H., Styles, C. A., and Fink, G. R. (1996). Saccharomyces cerevisiae S288C has a mutation in FLO8, a gene required for filamentous growth. Genetics 144, 967-978.

Liu, Z., and Butow, R. A. (1999). A transcriptional switch in the expression of yeast tricarboxylic acid cycle genes in response to a reduction or loss of respiratory function. Mol. Cell. Biol. 19, 6720-6728. doi: 10.1128/MCB.19.10.6720

Liu, Z., and Butow, R. A. (2006). Mitochondrial retrograde signaling. Annu. Rev. Genet. 40, 159-185. doi: 10.1146/annurev.genet.40.110405.090613

Liu, Z., Sekito, T., Spirek, M., Thornton, J., and Butow, R. A. (2003). Retrograde signaling is regulated by the dynamic interaction between Rtg2p and Mks1p. Mol. Cell 12, 401-411. doi: 10.1016/S1097-2765(03)00285-5

Ljungdahl, P. O., and Daignan-Fornier, B. (2012). Regulation of amino acid, nucleotide, and phosphate metabolism in Saccharomyces cerevisiae. Genetics 190, 885-929. doi: 10.1534/genetics.111.133306

Lleixà, J., Martin, V., Portillo Mdel, C., Carrau, F., Beltran, G., and Mas, A. (2016). Comparison of fermentation and wines produced by inoculation of Hanseniaspora vineae and Saccharomyces cerevisiae. Front. Microbiol. 7:338. doi: $10.3389 /$ fmicb. 2016.00338
Lo, W. S., and Dranginis, A. M. (1996). FLO11, a yeast gene related to the STA genes, encodes a novel cell surface flocculin. J. Bacteriol. 178, 7144-7151. doi: 10.1128/jb.178.24.7144-7151.1996

Lorenz, M. C., Cutler, N. S., and Heitman, J. (2000). Characterization of alcoholinduced filamentous growth in Saccharomyces cerevisiae. Mol. Biol. Cell 11, 183-199. doi: 10.1091/mbc.11.1.183

Lorenz, M. C., and Heitman, J. (1998). Regulators of pseudohyphal differentiation in Saccharomyces cerevisiae identified through multicopy suppressor analysis in ammonium permease mutant strains. Genetics 150, 1443-1457.

Madhani, H. D., and Fink, G. R. (1998). The control of filamentous differentiation and virulence in fungi. Trends Cell Biol. 8, 348-353. doi: 10.1016/S0962-8924(98)01298-7

Marullo, P., Aigle, M., Bely, M., Masneuf-Pomarède, I., Durrens, P., Dubourdieu, D., et al. (2007). Single QTL mapping and nucleotide-level resolution of a physiologic trait in wine Saccharomyces cerevisiae strains. FEMS Yeast Res. 7, 941-952. doi: 10.1111/j.1567-1364.2007.00252.x

McCartney, R. R., and Schmidt, M. C. (2001). Regulation of Snf1 kinase. Activation requires phosphorylation of threonine 210 by an upstream kinase as well as a distinct step mediated by the Snf4 subunit. J. Biol. Chem. 276, 36460-36466. doi: 10.1074/jbc.M104418200

Measday, V., Moore, L., Retnakaran, R., Lee, J., Donoviel, M., Neiman, A. M., et al. (1997). A family of cyclin-like proteins that interact with the Pho85 cyclindependent kinase. Mol. Cell. Biol. 17, 1212-1223. doi: 10.1128/MCB.17.3.1212

Miller, M. B., and Bassler, B. L. (2001). Quorum sensing in bacteria. Annu. Rev. Microbiol. 55, 165-199. doi: 10.1146/annurev.micro.55. 1.165

Moffat, J., and Andrews, B. (2004). Late-G1 cyclin-CDK activity is essential for control of cell morphogenesis in budding yeast. Nat. Cell Biol. 6, 59-66. doi: $10.1038 /$ ncb 1078

Mortimer, R. K., and Johnston, J. R. (1986). Genealogy of principal strains of the yeast genetic stock center. Genetics 113, 35-43.

Mosch, H. U., Kubler, E., Krappmann, S., Fink, G. R., and Braus, G. H. (1999) Crosstalk between the Ras2p-controlled Mitogen- activated Protein Kinase and cAMP Pathways during Invasive Growth of Saccharomyces cerevisiae. Mol. Biol. Cell 10, 1325-1335. doi: 10.1091/mbc.10.5.1325

Mosch, H. U., Roberts, R. L., and Fink, G. R. (1996). Ras2 signals via the Cdc42/Ste20/mitogen-activated protein kinase module to induce filamentous growth in Saccharomyces cerevisiae. Proc. Natl. Acad. Sci. U.S.A. 93, 5352-5356 doi: 10.1073/pnas.93.11.5352

Niu, W., Li, Z., Zhan, W., Iyer, V. R., and Marcotte, E. M. (2008). Mechanisms of cell cycle control revealed by a systematic and quantitative overexpression screen in S. cerevisiae. PLoS Genet 4:e1000120. doi: 10.1371/journal.pgen.1000120

Novo, M., Bigey, F., Beyne, E., Galeote, V., Gavory, F., Mallet, S., et al. (2009). Eukaryote-to-eukaryote gene transfer events revealed by the genome sequence of the wine yeast Saccharomyces cerevisiae EC1118. Proc. Natl. Acad. Sci. U.S.A. 106, 16333-16338. doi: 10.1073/pnas.0904673106

Oppenheim, R. D., Creek, D. J., Macrae, J. I., Modrzynska, K. K., Pino, P., Limenitakis, J., et al. (2014). BCKDH: the missing link in apicomplexan mitochondrial metabolism is required for full virulence of Toxoplasma gondii and Plasmodium berghei. PLoS Pathog. 10: e1004263. doi: 10.1371/journal.ppat.1004263

Orlova, M., Ozcetin, H., Barrett, L., and Kuchin, S. (2010). Roles of the Snfl-activating kinases during nitrogen limitation and pseudohyphal differentiation in Saccharomyces cerevisiae. Eukaryot. Cell 9, 208-214. doi: 10.1128/EC.00216-09

Palecek, S. P., Parikh, A. S., and Kron, S. J. (2000). Genetic analysis reveals that FLO11 upregulation and cell polarization independently regulate invasive growth in Saccharomyces cerevisiae. Genetics 156, 1005-1023.

Padilla, B., García-Fernández, D., González, B., Izidoro, I., Esteve-Zarzoso, B., Beltran, G, et al. (2016). Yeast biodiversity from DOQ priorat uninoculated fermentations. Front. Microbiol. 7:930. doi: 10.3389/fmicb.2016.00930

Palkova, Z., Janderova, B., Gabriel, J., Zikanova, B., Pospisek, M., and Forstová, J. (1997). Ammonia mediates communication between yeast colonies. Nature 390, 532-536. doi: 10.1038/37398

Pan, X., and Heitman, J. (2002). Protein kinase A operates a molecular switch that governs yeast pseudohyphal differentiation. Mol. Cell. Biol. 22, 3981-3993. doi: 10.1128/MCB.22.12.3981-3993.2002 
Parsek, M. R., and Greenberg, E. P. (2005). Sociomicrobiology: the connections between quorum sensing and biofilms. Trends Microbiol. 13, 27-33. doi: 10.1016/j.tim.2004.11.007

Petrakis, T. G., Wittschieben, B. O., and Svejstrup, J. Q. (2004). Molecular architecture, structure-function relationship, and importance of the Elp3 subunit for the RNA binding of holo-elongator. J. Biol. Chem. 279, 32087-32092. doi: 10.1074/jbc.M403361200

Polvi, E. J., Li, X., O'Meara, T. R., Leach, M. D., and Cowen, L. E. (2015). Opportunistic yeast pathogens: reservoirs, virulence mechanisms, and therapeutic strategies. Cell. Mol. Life Sci. 72, 2261-2287. doi: 10.1007/s00018-015-1860-z

Prunuske, A. J., Waltner, J. K., Kuhn, P., Gu, B., and Craig, E. A. (2012). Role for the molecular chaperones Zuol and Sszl in quorum sensing via activation of the transcription factor Pdr1. Proc. Natl. Acad. Sci. U.S.A. 109, 472-477. doi: 10.1073/pnas.1119184109

Querol, A., Huerta, T., Barrio, E., and Ramon, D. (1992). Dry yeast-strain for use in fermentation of Alicante wines-selection and DNA patterns. J. Food Sci. 57, 183-185. doi: 10.1111/j.1365-2621.1992.tb05451.x

Ramond, E., Gesbert, G., Rigard, M., Dairou, J., Dupuis, M., Dubail, I., et al. (2014). Glutamate utilization couples oxidative stress defense and the tricarboxylic acid cycle in Francisella phagosomal escape. PLoS Pathog. 10:e1003893. doi: 10.1371/journal.ppat.1003893

Ribéreau-Gayon, P., Dubordieu, D., Donèche, B., and Lonvaud, A. E. (2000). Handbook of Enology, the Microbiology of Wine and Vinifications. Chichester: John Wiley \& Sons.

Roberts, R. L., and Fink, G. R. (1994). Elements of a single MAP kinase cascade in Saccharomyces cerevisiae mediate two developmental programs in the same cell type: mating and invasive growth. Genes Dev. 8, 2974-2985. doi: 10.1101/gad.8.24.2974

Robertson, L. S., Causton, H. C., Young, R. A., and Fink, G. R. (2000). The yeast A kinases differentially regulate iron uptake and respiratory function. Proc. Natl. Acad. Sci. U.S.A. 97, 5984-5988. doi: 10.1073/pnas.100113397

Robertson, L. S., and Fink, G. R. (1998a). The three yeast A kinases have specific signaling functions in pseudohyphal growth. Proc. Natl. Acad. Sci. U.S.A. 95, 13783-13787. doi: 10.1073/pnas.95.23.13783

Robertson, L. S., and Fink, G. R. (1998b). The three yeast A kinases have specific signaling functions in pseudohyphal growth. Proc. Natl. Acad. Sci. U.S.A. 95, 13783-13787. doi: 10.1073/pnas.95.23.13783

Rose, M. D., Winston, F., and Hieter, P. (1990). Methods in Yeast Genetics. Cold Spring Harbor, NY: Cold Spring Harbor Laboratory Press.

Ruiz-Roig, C., Noriega, N., Duch, A., Posas, F., and de Nadal, E. (2012). The Hog1 SAPK controls the Rtg1/Rtg3 transcriptional complex activity by multiple regulatory mechanisms. Mol. Biol. Cell 23, 4286-4296. doi: 10.1091/mbc.E12-04-0289

Rumbaugh, K. P., Diggle, S. P., Watters, C. M., Ross-Gillespie, A., Griffin, A. S., West, S. A. et al. (2009). Quorum sensing and the social evolution of bacterial virulence. Curr. Biol. 19, 341-345. doi: 10.1016/j.cub.2009. 01.050

Rupp, S., Summers, E., Lo, H. J., Madhani, H. D., and Fink, G. R. (1999b). MAP kinase and CAMP filamentation signaling pathways converge on the unusually large promoter of the yeast FLO11 gene. EMBO J. 18, 1257-1269. doi: 10.1093/emboj/18.5.1257

Rupp, S., Summers, E., Lo, H. J., Madhani, H., and Fink, G. (1999a). MAP kinase and cAMP filamentation signaling pathways converge on the unusually large promoter of the yeast FLO11 gene. EMBO J. 18, 1257-1269. doi: 10.1093/emboj/18.5.1257

Ryan, O., Shapiro, R. S., Kurat, C. F., Mayhew, D., Baryshnikova, A., Chin, B., et al. (2012). Global gene deletion analysis exploring yeast filamentous growth. Science 337, 1353-1356. doi: 10.1126/science.1224339

Sagot, I., Klee, S. K., and Pellman, D. (2002). Yeast formins regulate cell polarity by controlling the assembly of actin cables. Nat. Cell Biol. 4, 42-50. doi: $10.1038 /$ ncb719

Saito, H. (2010). Regulation of cross-talk in yeast MAPK signaling pathways. Curr. Opin. Microbiol. 13, 677-683. doi: 10.1016/j.mib.2010. 09.001

Schütz, M., and Gafner, J. (1994). Dynamics of the yeast strain population during spontaneous alcoholic fermentation determined by CHEF gel electrophoresis. J. Appl. Bacteriol. 19, 253-257. doi: 10.1111/j.1472-765X.1994. tb00957.x

Sekito, T., Liu, Z., Thornton, J., and Butow, R. A. (2002). RTG-dependent mitochondria-to-nucleus signaling is regulated by MKS1 and is linked to formation of yeast Prion [URE3]. Mol. Biol. Cell 13, 795-804. doi: 10.1091/mbc.01-09-0473

Sharma, M., and Prasad, R. (2011). The quorum-sensing molecule farnesol is a modulator of drug efflux mediated by $\mathrm{ABC}$ multidrug transporters and synergizes with drugs in Candida albicans. Antimicrob. Agents Chemother. 55, 4834-4843. doi: 10.1128/AAC.00344-11

Shemer, R., Meimoun, A., Holtzman, T., and Kornitzer, D. (2002). Regulation of the transcription factor Gcn 4 by Pho85 cyclin Pcl5. Mol. Cell. Biol. 22, 5395-5404. doi: 10.1128/MCB.22.15.5395-5404.2002

Sidari, R., Caridi, A., and Howell, K. S. (2014). Wild Saccharomyces cerevisiae strains display biofilm-like morphology in contact with polyphenols from grapes and wine. Int. J. Food Microbiol. 189, 146-152. doi: 10.1016/j.ijfoodmicro.2014.08.012

Sprague, G. F. Jr., and Winans, S. C. (2006). Eukaryotes learn how to count: quorum sensing by yeast. Genes Dev. 20, 1045-1049. doi: 10.1101/gad.14 32906

Starovoytova, A. N., Sorokin, M. I., Sokolov, S. S., Severin, F. F., and Knorre, D. A. (2013). Mitochondrial signaling in Saccharomyces cerevisiae pseudohyphae formation induced by butanol. FEMS Yeast Res. 13, 367-374. doi: 10.1111/1567-1364.12039

Suzzi, G., Romano, P., and Zambonelli, C. (1984). Flocculation of wine yeasts: frequency, differences, and stability of the character. Can. J. Microbiol. 30, 36-39. doi: 10.1139/m84-006

Svejstrup, J. Q. (2007). Elongator complex: how many roles does it play? Curr. Opin. Cell Biol. 19, 331-336. doi: 10.1016/j.ceb.2007.04.005

Toda, T., Uno, I., Ishikawa, T., Powers, S., Kataoka, T., Broek, D., et al. (1985). In yeast, RAS proteins are controlling elements of adenylate cyclase. Cell 40, 27-36. doi: 10.1016/0092-8674(85) 90305-8

Tokai, M., Kawasaki, H., Kikuchi, Y., and Ouchi, K. (2000). Cloning and characterization of the CSF1 gene of Saccharomyces cerevisiae, which is required for nutrient uptake at low temperature. J. Bacteriol. 182, 2865-2868. doi: 10.1128/JB.182.10.2865-2868.2000

Tu, D., Graziano, B. R., Park, E., Zheng, W., Li, Y., Goode, B. L., et al. (2012). Structure of the formin-interaction domain of the actin nucleationpromoting factor Bud6. Proc. Natl. Acad. Sci. U.S.A. 109, E3424-3433. doi: 10.1073/pnas.1203035109

Urban, J., Soulard, A., Huber, A., Lippman, S., Mukhopadhyay, D., Deloche, O., et al. (2007). Sch9 is a major target of TORC1 in Saccharomyces cerevisiae. Mol. Cell 26, 663-674. doi: 10.1016/j.molcel.2007.04.020

Wang, C., García-Fernández, D., Mas, A., and Esteve-Zarzoso, B., (2015). Fungal diversity in grape must and wine fermentation assessed by massive sequencing, quantitative PCR and DGGE. Front. Microbiol. 23:1156. doi: $10.3389 /$ fmicb. 2015.01156

Wei, W., McCusker, J. H., Hyman, R. W., Jones, T., Ning, Y., Cao, Z., et al. (2007). Genome sequencing and comparative analysis of Saccharomyces cerevisiae strain YJM789. Proc. Natl. Acad. Sci. U.S.A. 104, 12825-12830. doi: 10.1073/pnas.0701291104

Wei, Y., and Zheng, X. F. (2009). Sch9 partially mediates TORC1 signaling to control ribosomal RNA synthesis. Cell Cycle 8, 4085-4090. doi: $10.4161 /$ cc.8.24.10170

Westfall, P. J., Ballon, D. R., and Thorner, J. (2004). When the stress of your environment makes you go HOG wild. Science 306, 1511-1512. doi: $10.1126 /$ science. 1104879

Westman, J. O., and Franzen, C. J. (2015). Current progress in high cell density yeast bioprocesses for bioethanol production. Biotechnol. J. 10, 1185-1195. doi: 10.1002/biot.201400581

Williams, T. C., Averesch, N. J., Winter, G., Plan, M. R., Vickers, C. E., Nielsen, L. K., et al. (2015). Quorum-sensing linked RNA interference for dynamic metabolic pathway control in Saccharomyces cerevisiae. Metab. Eng. 29, 124-134. doi: 10.1016/j.ymben.2015.03.008

Winkler, G. S., Petrakis, T. G., Ethelberg, S., Tokunga, M., Erdjument-Bromage, H., Tempst, P., et al. (2001). RNA polymerase II elongator holoenzyme is 
composed of two discrete subcomplexes. J. Biol. Chem. 276, 32743-32749. doi: 10.1074/jbc.M105303200

Woods, A., Munday, M. R., Scott, J., Yang, X., Carlson, M., and Carling, D. (1994). Yeast SNF1 is functionally related to mammalian AMP-acitvate protein kinase and regulates acetyl-CoA carboxylase in vivo. J. Biol. Chem. 269, 19509-19515.

Wuster, A., and Babu, M. M. (2010). Transcriptional control of the quorum sensing response in yeast. Mol. Biosyst. 6, 134-141. doi: 10.1039/B913579K

Xu, T., Shively, C. A., Jin, R., Eckwahl, M. J., Dobry, C. J., Song, Q., et al. (2010). A profile of differentially abundant proteins at the yeast cell periphery during pseudohyphal growth. J. Biol. Chem. 285, 15476-15488. doi: 10.1074/jbc.M110. 114926

Young, E. T., and Pilgrim, D. (1985). Isolation and DNA sequence of $\mathrm{ADH} 3$, a nuclear gene encoding the mitochondrial isozyme of alcohol dehydrogenase in Saccharomyces cerevisiae. Mol. Cell. Biol. 5, 3024-3034. doi: 10.1128/MCB.5.11.3024
Zaman, S., Lippman, S. I., Zhao, X., and Broach, J. R. (2008). How Saccharomyces Responds to Nutrients. Annu. Rev. Genet. 42, 27-81. doi: 10.1146/annurev.genet.41.110306.130206

Zupan, J., and Raspor, P. (2008). Quantitative agar-invasion assay. J. Microbiol. Methods 73, 100-104. doi: 10.1016/j.mimet.2008.02.009

Conflict of Interest Statement: The authors declare that the research was conducted in the absence of any commercial or financial relationships that could be construed as a potential conflict of interest.

Copyright (๑) 2017 González, Mas, Beltran, Cullen and Torija. This is an open-access article distributed under the terms of the Creative Commons Attribution License (CC $B Y)$. The use, distribution or reproduction in other forums is permitted, provided the original author(s) or licensor are credited and that the original publication in this journal is cited, in accordance with accepted academic practice. No use, distribution or reproduction is permitted which does not comply with these terms. 